\title{
Recent advancements in optical microstructure fabrication through glass molding process
}

(C) The Author(s) 2017. This article is published with open access at link.springer.com and journal.hep.com.cn

\begin{abstract}
Optical microstructures are increasingly applied in several fields, such as optical systems, precision measurement, and microfluid chips. Microstructures include microgrooves, microprisms, and microlenses. This paper presents an overview of optical microstructure fabrication through glass molding and highlights the applications of optical microstructures in mold fabrication and glass molding. The glass-mold interface friction and adhesion are also discussed. Moreover, the latest advancements in glass molding technologies are detailed, including new mold materials and their fabrication methods, viscoelastic constitutive modeling of glass, and microstructure molding process, as well as ultrasonic vibrationassisted molding technology.
\end{abstract}

Keywords optical microstructure, microgroove, microlens, glass molding process, single-point diamond cutting

\section{Introduction}

\subsection{Applications of optical microstructures}

\subsubsection{Optical imaging in optical systems}

Recently, the demand for 3D microsurface structures, such as microgrooves, micropyramids, microprisms, and microlenses, has been increasing in the optical industry. Components with microsurface structures, particularly microstructure arrays, yield new functions for light

Received September 6, 2016; accepted December 11, 2016

Tianfeng ZHOU, Zhiqiang LIANG ( $₫)$, Xibin WANG

Key Laboratory of Fundamental Science for Advanced Machining, Beijing Institute of Technology, Beijing 100081, China

E-mail: liangzhiqiang@bit.edu.cn

Xiaohua LIU, Yang LIU, Jiaqing XIE

School of Mechanical Engineering, Beijing Institute of Technology, Beijing 100081, China operation, thereby significantly improving the imaging quality of optical systems [1].

Microstructure arrays are configurations of several lenses or prisms in micro/nano scale. Microstructure arrays can provide various optical functions because of their special geometrical features. The basic types of microstructure arrays are displayed in Fig. 1 according to the element shape. The optical performance of microstructure arrays with element size ranging from 5 to $50 \mu \mathrm{m}$ is mainly achieved through their refraction and reflection properties. Through multiple imaging, microstructure arrays can raise the light energy utilization ratio and realize the miniaturization of optical systems. Moreover, combining different types of microstructure arrays can enhance beam guidance control, smart scan, and other complex functions (Fig. 2). These functions have driven the wide-scale application of microstructure arrays in liquid crystal displays, mobile phones, palm pilots, televisions, and other electronic products. An example of a microstructure based on the refraction principle is the wave-front sensor, which is composed of a microlens array and a charge-coupled device array.

The optical performance of microstructure arrays with element size ranging from 0.5 to $5 \mu \mathrm{m}$ is mainly dependent on their interference and diffraction reflection properties. Light passing through microstructure arrays can produce entirely different phenomena than those created with macro lenses. As shown in Fig. 3, microstructure arrays are equipped with both $1 \mathrm{D}$ and $2 \mathrm{D}$ diffraction. The complex design and cycle structures of microstructure arrays enable them to accomplish several functions, such as antireflection, polarization beam splitting, optical waveguide coupling, light beam transformation, and integration.

Optical component with microstructures using diffraction principle is most commonly used in diffraction grating. Diffraction grating is a component of optical devices that consist of a surface ruled with close, equidistant, and parallel lines to resolve light into the spectra. 


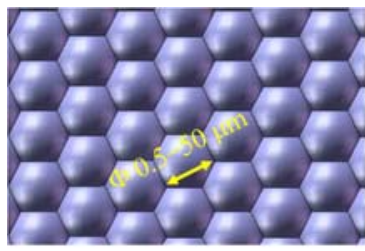

(a)

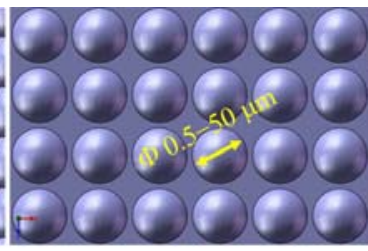

(b)

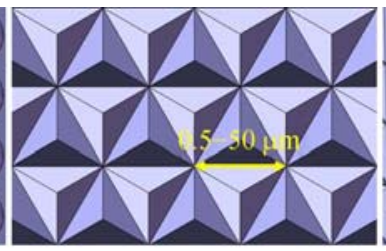

(c)

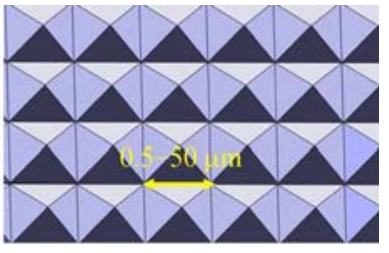

(d)

Fig. 1 Element shape of microstructure arrays: (a) Adjacent microlens arrays, (b) distributed microlens arrays, (c) triangular pyramid arrays, (d) rectangular pyramid arrays

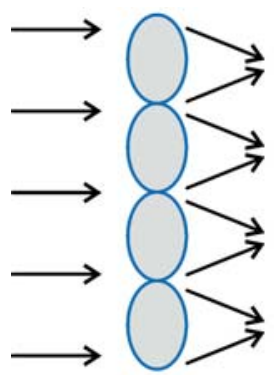

(a)

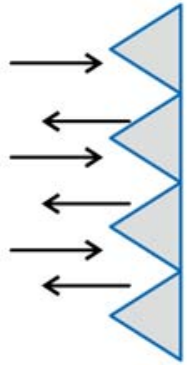

(b)

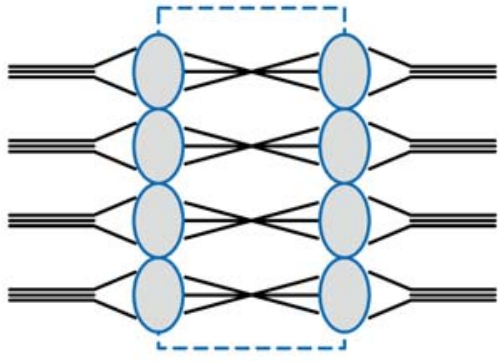

(c)

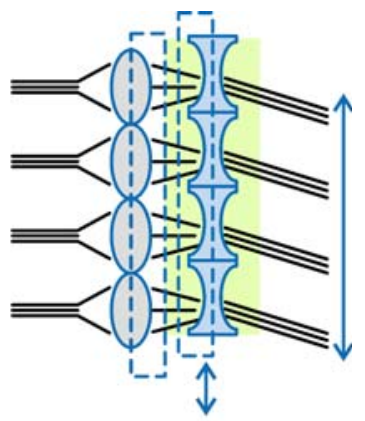

(d)

Fig. 2 Function and application of microstructure arrays with large element size. (a) Focus; (b) reflection; (c) beam guidance; (d) smart scan

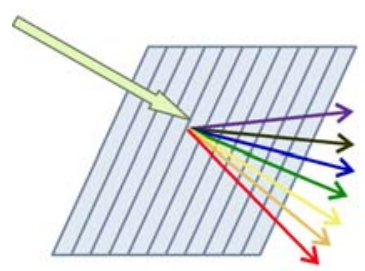

(a)

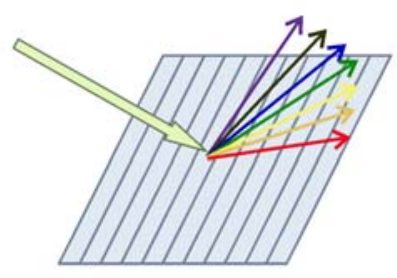

(b)

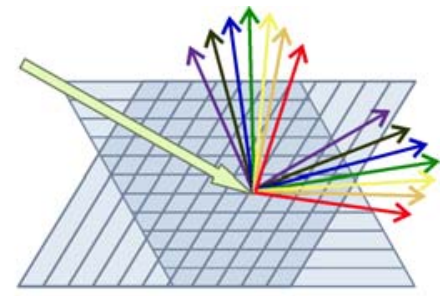

(c)

Fig. 3 Function and application of microstructure arrays with small element size. (a) 1D transmission diffraction; (b) 1D reflection diffraction; (c) 2D diffraction

1.1.2 Positioning sensor in machine tools and measurement equipment

The simplest positioning sensor is the grating ruler, which is used as the checkout gear in numerical control machine tools. In the installation of a grating ruler, the line on the indicator grating will generate a small angle with the line on the ruler grating. The lines on the two gratings cross each other and overlap, forming black fringes near the intersection and bright fringes in other places when light passes through the grating. These fringes are called Moiré fringes (Fig. 4).

Moire fringes change between bright and dark with the movement of grating. The system will output the pulse after signal processing, circuit amplification, shaping, and differentiation. Each output of a pulse is represented by the distance of a grid. Thus, the moving distance of the working table can be obtained by counting the pulses.

\subsection{Fabrication methods for optical microstructures}

The demand for optical microstructures has dramatically increased in various fields. However, microstructures are difficult to machine on hard and brittle material, including glass $[3,4]$.

Optical microstructures are generally produced through material removal processes, such as cutting [5], grinding [6], sand blasting [7-9], photolithography [10-12], wet/dry etching [13-16], focused ion beam (FIB) [17-19], and other methods [20-24]. Other strategies, such as microcutting of glass using micro-endmills and micro ultrasonic-assisted lapping, have also been reported $[25,26]$. These processes are effective and stable approaches for manufacturing microstructures on glass that facilitate glass microstructure fabrication. However, the overall cost of medium- to high-volume production of optical microstructures is extremely high because 


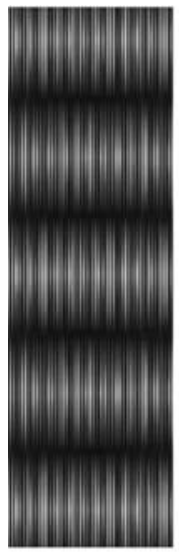

(a)

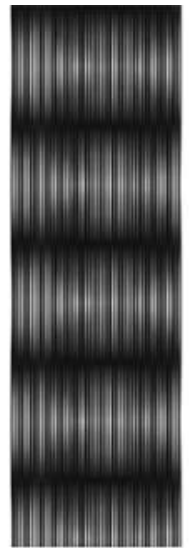

(b)

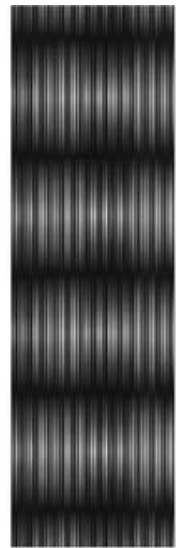

(c)

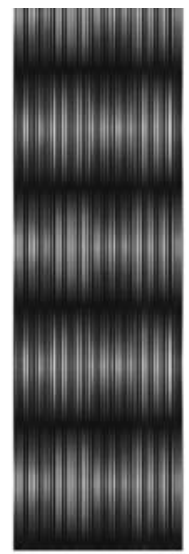

(d)

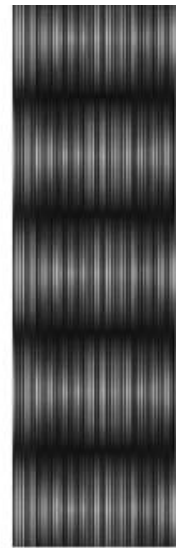

(e)

Fig. 4 Typical Moiré pattern formed by two superimposed Ronchi gratings rotated by an angle with displacement equal to: (a) Zero, (b) a quarter of the grating pitch, (c) half of the grating pitch, (d) three-quarters of the grating pitch, and (e) the grating pitch [2]

of the complexity and long cycle times of these processes.

Given that microstructuring techniques were first developed for high aspect ratios, the economic success of such techniques demand for cost-effective replication in large-scale series [27]. Microinjection molding and sheet nanoimprinting are gaining recognition as feasible manufacturing processes because of their capability to replicate the microstructure shape of the mold onto the substrate $[28,29]$, albeit only for plastic materials.

\subsection{Glass molding}

Glass molding process (GMP) is an alternative approach that produces glass optical microstructures by replicating the shape of the mold to the heated glass preforms without further machining processes [30-33]. Figure 5 shows the GMP technology of the microstructure array.

In terms of fabrication cost and process time, GMP is certainly an excellent approach for producing precision optical elements, such as aspherical and Fresnel lenses, diffractive optical elements (DOEs), and microprism and microlens arrays. Recent works [35-37] have also reported glass molding for microstructures, which can be alternatively called hot embossing or thermal imprinting.
In terms of production cost and environmental compatibility, hot compression molding is a promising manufacturing method for producing precision glass lenses with microgrooves. Hot compression molding can produce lenses having form accuracy, surface finish, and optical performance that are comparable to lenses manufactured through conventional techniques of material removal. Figure 6 shows the process flow of microgroove forming. The process can be divided into four stages according to the thermal cycle: Heating, pressing, annealing, and cooling. At the heating stage, a glass preform is placed on the lower mold. Inert gas, such as nitrogen $\left(\mathrm{N}_{2}\right)$, is flowed to purge the air in the machine chamber. The molds and the glass preform are then heated to the molding temperature by a heat source, such as infrared lamps (Fig. 6 (a)). At the pressing stage, the glass preform is pressed by closing the two mold halves (Fig. 6(b)). At the annealing stage, the formed lens is slowly cooled down while a small pressing load is maintained to release the internal stress (Fig. 6(c)). At the cooling stage, the glass lens is cooled rapidly to ambient temperature and released from the molds (Fig. 6(d)). Through these four stages, the shapes of the mold cores are precisely replicated to the glass lens.

However, several technical challenges associated with

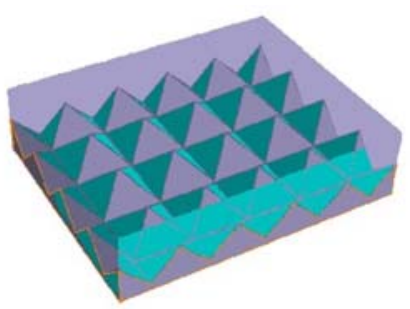

(a)

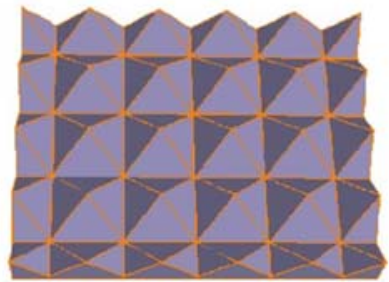

(b)

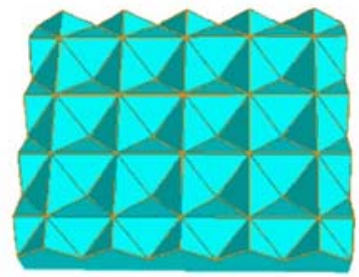

(c)

Fig. 5 Glass molding technology of microstructure array. (a) Forming schematic of the microstructure array; (b) mold with microstructures; (c) glass with microstructures [34] 


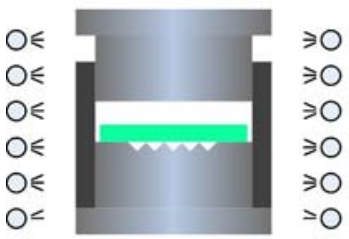

(a)

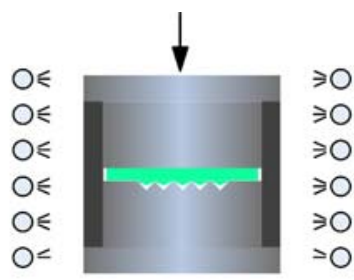

(b)

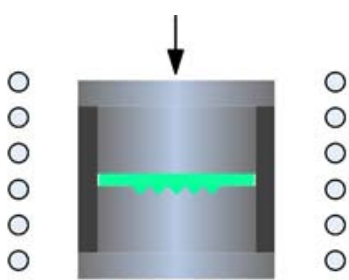

(c)

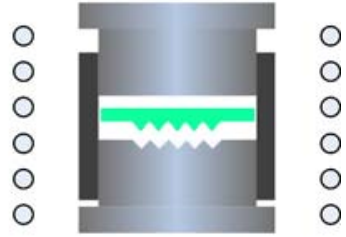

(d)

Fig. 6 Process flow of microgroove forming: (a) Heating, (b) pressing, (c) annealing, and (d) cooling

the molding process have prevented the application of the microgroove forming process for high-volume lens production. These challenges include thermal shrinkage of the lens upon cooling, optical surface finish, precise mold shape, mold life, and selection of process parameters [38].

\section{Microstructure mold fabrication}

\subsection{Fabrication methods for the microstructure mold}

To extend the GMP method to creating microstructures on glass surfaces, the microstructure mold should be machined with high accuracy and efficiency. Hard materials, such as silicon carbide ( $\mathrm{SiC}$ ), tungsten carbide (WC), and fused silica, are ideal mold materials for continuous surfaces because of their high hardness and toughness under molding conditions.

Although creating microstructures on these hard materials have been attempted several times, the low-cost fabrication of microstructures with desirable shape and accuracy has not yet been realized [39]. Grinding and milling are conventional ways for the high-accuracy production of microstructures on hard materials. Nevertheless, the costs of these processes for medium- to highvolume production are extremely high [40]. Micro-electric discharge machining and micro-electrochemical machining have been applied in the microstructure fabrication on WC. Although these methods can machine complex 3D shapes regardless of the material's hardness [41-45], the surface roughness is low, which hinders the creation of the optical surface. A popular strategy for producing microstructures on molds is indentation, which is a patented process developed by Yan et al. [46]. This technique is based on the advantage of having a negligible small tool wear and a stable manufacturing process. In addition, various 3D shapes can be realized by reactive ion etching, which utilizes chemically reactive plasma to remove materials deposited on $\mathrm{SiC}$ molds [47-49]. In terms of the process rate, roughness, and shape of the machined structure, laser technique is also an effective approach for microstructure mold fabrication. Femto-second laser combined with FIB milling can realize the rapid fabrication of high-quality microstructures on wide surface areas [50].
2.2 Advancements of microstructure fabrication on nickel phosphide mold

\subsubsection{Application of the new mold material}

As mentioned, microstructure molds made of hard materials are difficult to produce. However, single-point diamond cutting is a promising approach for creating microstructures, provided that a new material can be coated on the WC mold surface for the cutting process. This new material must possess excellent machinability for microstructure fabrication and high hardness to achieve a durable mold.

The electro-less deposition of nickel (Ni) in a bath containing hypophosphite was first observed by Wurtz [51] in 1844 and was then introduced to industrial application by Brenner and Riddell in 1946 and 1947 [52,53]. Since then, electro-less nickel phosphide (Ni-P) has emerged as an outstanding hard coating material because of its strong hardness, excellent corrosion resistance, and antiwear property. Given that the shape deformation and machinability of the Ni-P layer significantly change under different phosphorus contents, the effect of the phosphorus content on the thermal phase transformation and microstructure evolution during heating has attracted considerable research attention $[54,55]$. The preparation process of the Ni-P plating mold and the finished Ni-P plating mold are depicted in Fig. 7.

\subsubsection{Microstructure generation through diamond cutting}

The application of ultra-precision machining with diamond tools has rapidly grown in the manufacture of highprecision machined parts for advanced industrial applications [56]. The outstanding hardness and crystalline structure of diamond tools promote the fabrication of microstructures on Ni-P plating materials with submicron form accuracy and surface roughness in the nanometer range [57]. First, the Ni-P layer is coated on the substrate through electro-less plating method. Microstructures are then created on the Ni-P surface through single-diamond point cutting. Finally, the shape of the microstructures is replicated on the glass surface through GMP. By utilizing $\mathrm{V}$-shaped diamond tools, microstructures can be generated on the Ni-P plating layer, as shown in Fig. 8(a). Similarly, 


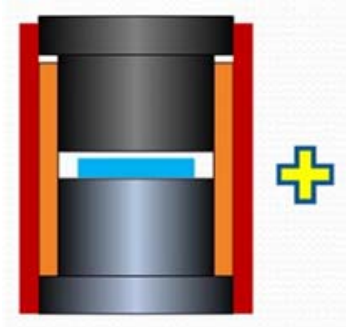

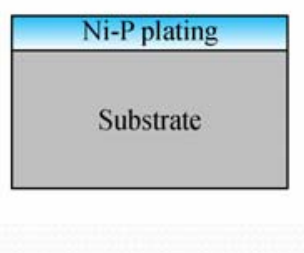

(a)

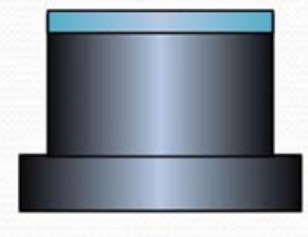

Fig. 7 (a) Preparation process of the Ni-P plating mold; (b) photograph of Ni-P plating mold

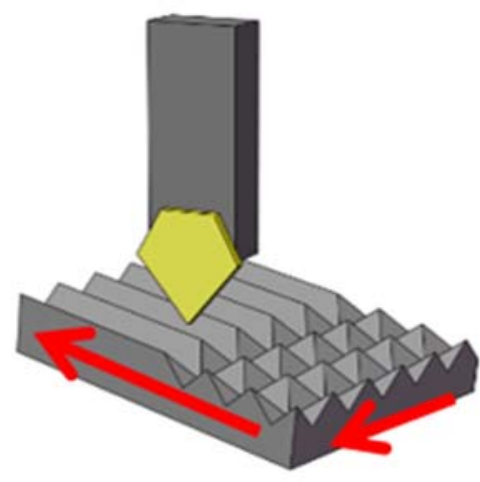

(a)

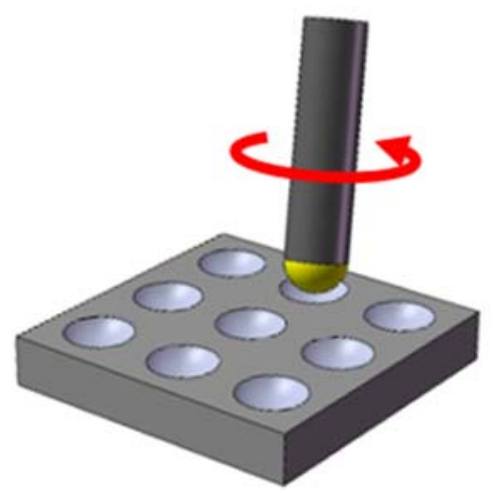

(b)

Fig. 8 Single-point diamond cutting process. (a) Microgroove arrays; (b) microlens arrays with the use of R-shaped diamond milling tools, microlens arrays can be formed through high-speed milling, as shown in Fig. 8(b).

However, the crystal transition of electro-less Ni-P would occur in amorphous materials once the temperature exceeds $400{ }^{\circ} \mathrm{C}$ [58], causing mold surface deformation and diminishing the accuracy of glass molding. To avoid mold surface deformation and achieve accurate and precise fabrication of microstructures for high-quality mold, an initial heat treatment method is proposed to eliminate irregular concave deformation during the crystallization process [59]. The amorphous plating is heated to the annealing temperature (approximately $600{ }^{\circ} \mathrm{C}$ ) to ensure the complete transformation into the crystalline state. The improved procedure of fabricating microgroove mold on crystallized Ni-P plating is presented in Fig. 9. In this way, less deformation of the mold occurs under the condition of GMP, and microstructure machining on the mold through single-point diamond cutting can be performed on the ultra-precision cutting machine $\left(\mathrm{Nanoform}^{\circledR} \mathrm{X}\right.$, Precitech Corp., United States), as shown in Fig. 10.

Although diamond cutting on the Ni-P plating can be utilized to fabricate microstructures on the mold, the machining process is still hindered by many challenges [60]. Burr adversely influences the mold surface roughness and form accuracy during the mold machining process [61-63]. Burr easily forms at the microstructure edge when ductile material is cut, as shown in Fig. 11. The mechanism of the burr formation can be revealed by considering the edge radius of the diamond cutting tool and the cutting

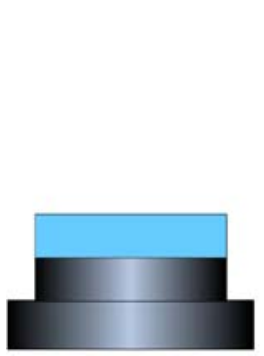

(a)

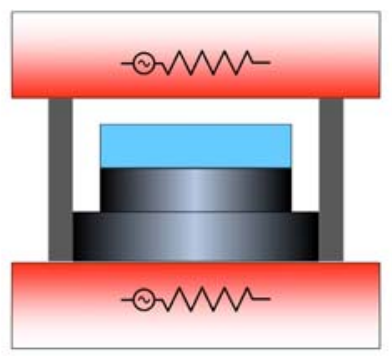

(b)

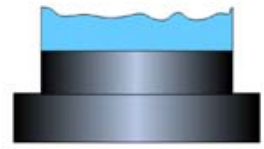

(c)

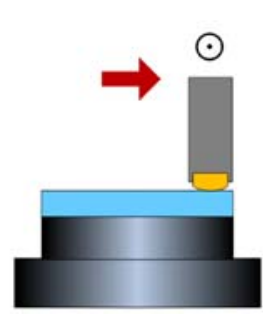

(d)

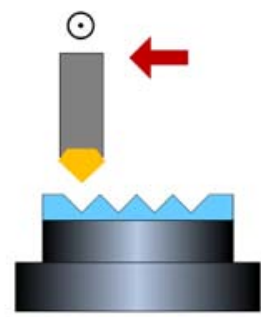

(e)

Fig. 9 Improved method of fabricating microgroove mold on crystalline Ni-P plating: (a) Amorphous Ni-P, (b) crystallization in GMP, (c) deformation in advance, (d) flattening, and (e) microgrooving on the crystalline Ni-P plating [59] 


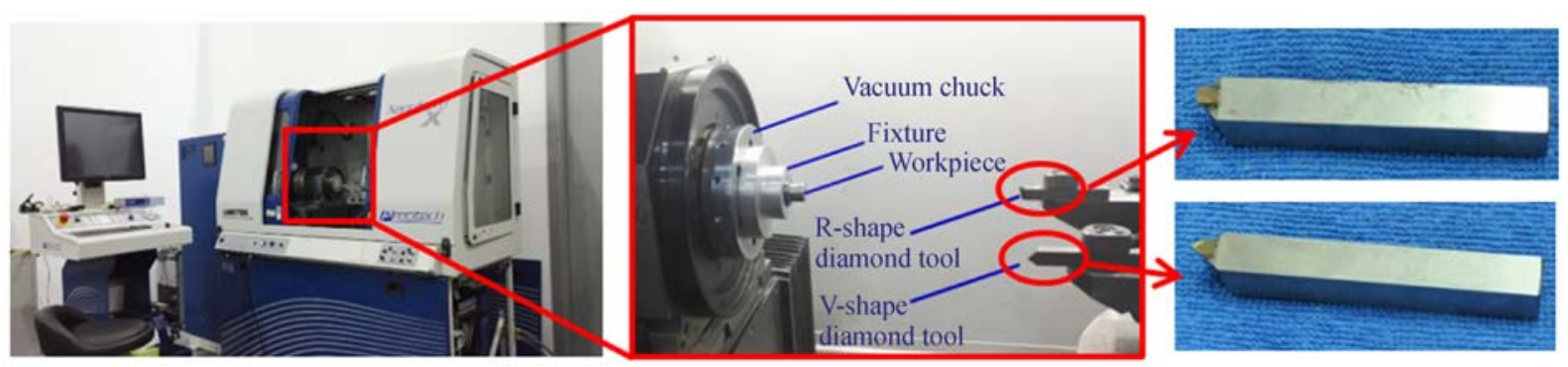

Fig. 10 Photograph of ultra-precision cutting machine (Nanoform ${ }^{\circledR}$ X, Precitech Corp., United States) [59]

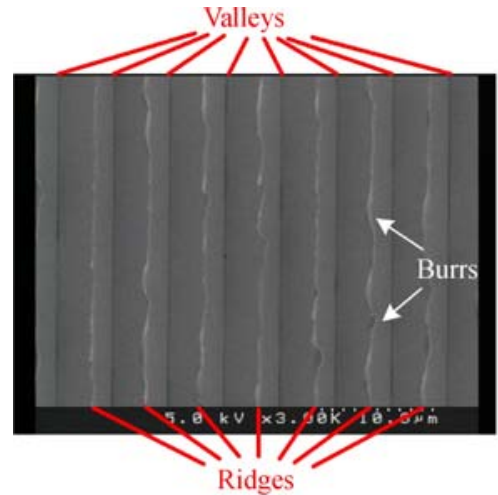

(a)

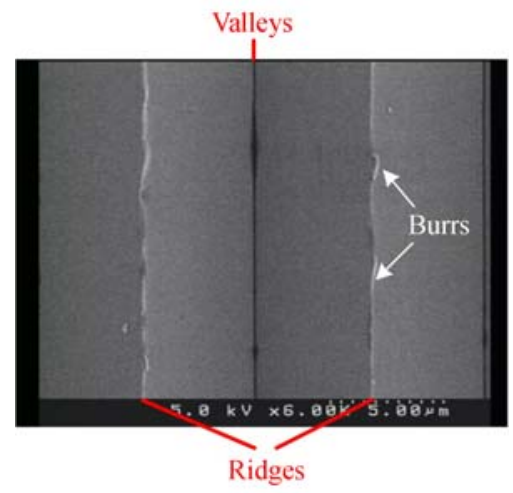

(b)

Fig. 11 SEM photographs at different magnifications showing burrs in machining process of microgroove arrays: (a) $3 \mathrm{k}$, (b) $6 \mathrm{k}$ depth of the workpiece material. Burr formation can be effectively eliminated by using a diamond tool with an edge radius of $57 \mathrm{~nm}$ instead of $100 \mathrm{~nm}$. However, as the cutting depth is decreased, more burrs are generated again. Thus, an approach that optimizes the nose radius and the cutting depth to minimize burr formation is established to generate fine microgrooves.

Chipping is another defect in the mold machining process, as shown in Fig. 12. Many attempts have been made to optimize the processing parameters and consequently reduce mold defects. With the advancements in the machining process and the exploration of the removal principle for Ni-P plating material, microstructure molds with high form accuracy and low surface roughness can be obtained. Figure 13 shows fine microgroove and micropyramid molds created through single-point diamond cutting.

\section{Molding process of microstructures}

\subsection{Modeling and simulation of microstructure molding}

\subsubsection{D microstructure modeling}

With the recent advances in numerical simulation capabilities and computing technology, finite element method can address issues that some variables are remarkably difficult to experimentally measure by providing deeper insight into the process and performance

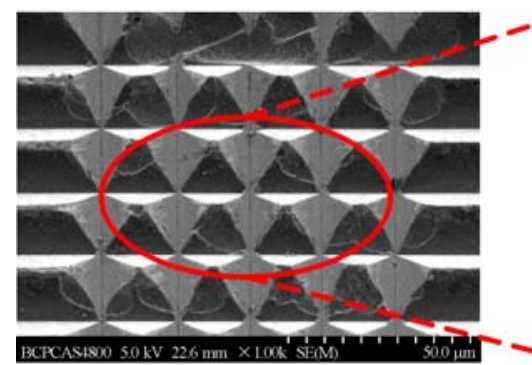

(a)

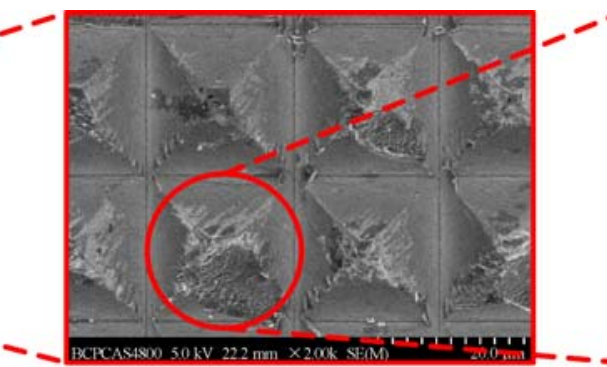

(b)

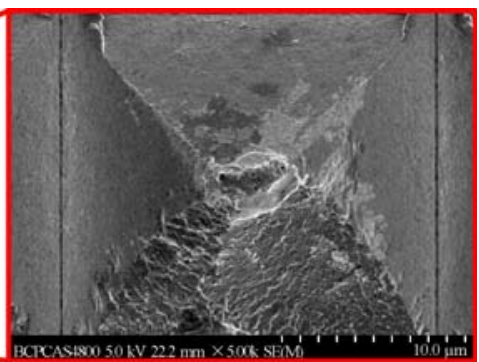

(c)

Fig. 12 SEM photographs at different magnifications showing microgroove arrays with edge chipping: (a) $1 \mathrm{k}$, (b) $2 \mathrm{k}$, and (c) $5 \mathrm{k}$ 


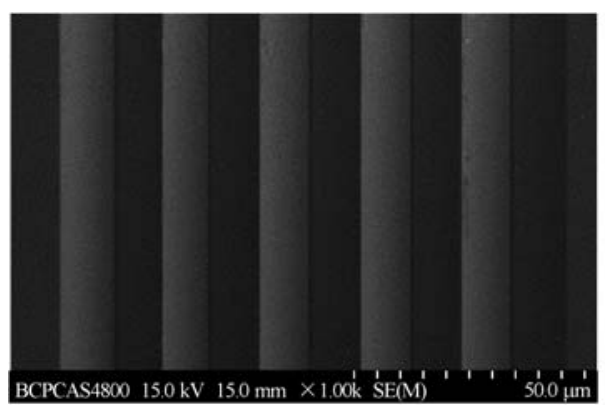

(a)

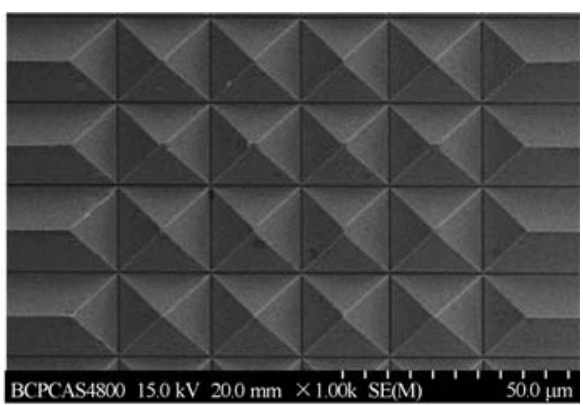

(b)

Fig. 13 SEM photographs showing: (a) Fine microgrooves and (b) fine micropyramids machined through single-point diamond cutting

prediction [64]. However, a reliable simulation model requires an accurate representation of materials with temperature-dependent mechanical and thermal properties. Lens molding is typically performed at a temperature range of $150-200^{\circ} \mathrm{C}$ above the glass transition temperature $\left(T_{\mathrm{g}}\right)$, at which the glass viscosity generally lies between $10^{7.6}$ and $10^{9.0} \mathrm{~Pa} \cdot \mathrm{s}$ [65]. In this temperature range, which is also referred to as the transition temperature range, the glass can be described as a viscoelastic material exhibiting stress relaxation. A general Maxwell model is established to describe the deformation during the pressing stage, as shown in Fig. 14 [66]. The time-dependent response is characterized by the deviatoric terms:

$$
\sigma(t)=\int_{0}^{t} G(t-\tau) \frac{\mathrm{d} \varepsilon}{\mathrm{d} \tau} \mathrm{d} \tau,
$$

where, $\sigma$ and $\varepsilon$ are the stress and strain, respectively. Equation (1) is evaluated for a current time $t$ based on the past time $\tau . G(t-\tau)$ is not a constant value but is represented by a Prony series, as shown in Eq. (2):

$$
G(t)=G_{0} \sum_{i=1}^{n} w_{i} \mathrm{e}^{-\frac{t}{t_{\mathrm{ri}}}}
$$

where $w_{i}$ is the relative moduli, and $t_{\mathrm{r} i}$ is the reduced time that describes the shift in time resulting from the temperature.

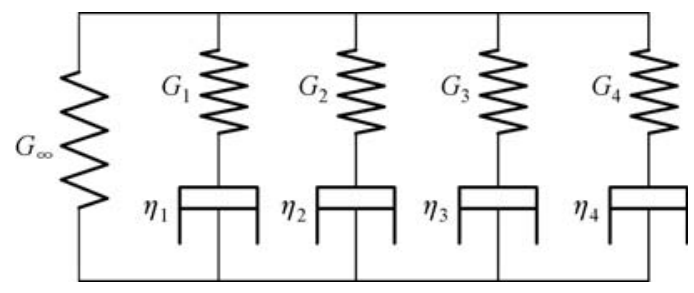

Fig. 14 General Maxwell model for describing the viscoelasticity of glass in the transition region

Figure 15 [35] shows the 2D simulation model of the GMP for microgrooves. The upper mold, which is flat and fixed at the top, and the lower mold with microgrooves will move upward to press the softened glass. Simulation results are obtained, and Fig. 16 [35] shows the equivalent stress distribution at the displacement of $15 \mu \mathrm{m}$ at $570{ }^{\circ} \mathrm{C}$.

\subsubsection{D microstructure modeling}

2D numerical simulation is used to illustrate the details of the GMP for microstructures, and the molding condition is optimized. However, 2D simulation cannot reveal the glass material flow among microstructure forming, such as microgrooves and micropyramids, because the crosssection of the V-groove is the same as that of the pyramid at the vertex. Therefore, 3D simulation must be incorporated in the numerical analyses of micropyramid forming, and the General Maxwell model is extended to the 3D simulation. Figure 17 [36] shows the 3D models of the GMP for microgrooves and micropyramids. Figures 18 and 19 [36] illustrate the stress and strain distributions for microgrooves and micropyramids.

\subsection{Glass molding process for microstructures}

\subsubsection{Glass molding equipment and molding conditions}

Different molding machines are widely used to conduct the GMP at high temperatures. Commercially available machines include two leading machines that are discussed in this section. Both of these machines provide the capability and flexibility required for scientific research and industrial practice, i.e., precise control over the mold position, load, and temperature while incorporating an extremely flexible design that can accommodate numerous tests.

1) Glass molding machine PFLF7-60A

Figure 20 shows the photograph of the glass molding machine PFLF7-60A, and Fig. 21 depicts its basic structure and functional features.

The machine is equipped with a drive system, a force adaptive control, a precision position control, and a data collector. Basic adjustments of the machine are introduced in the following. 


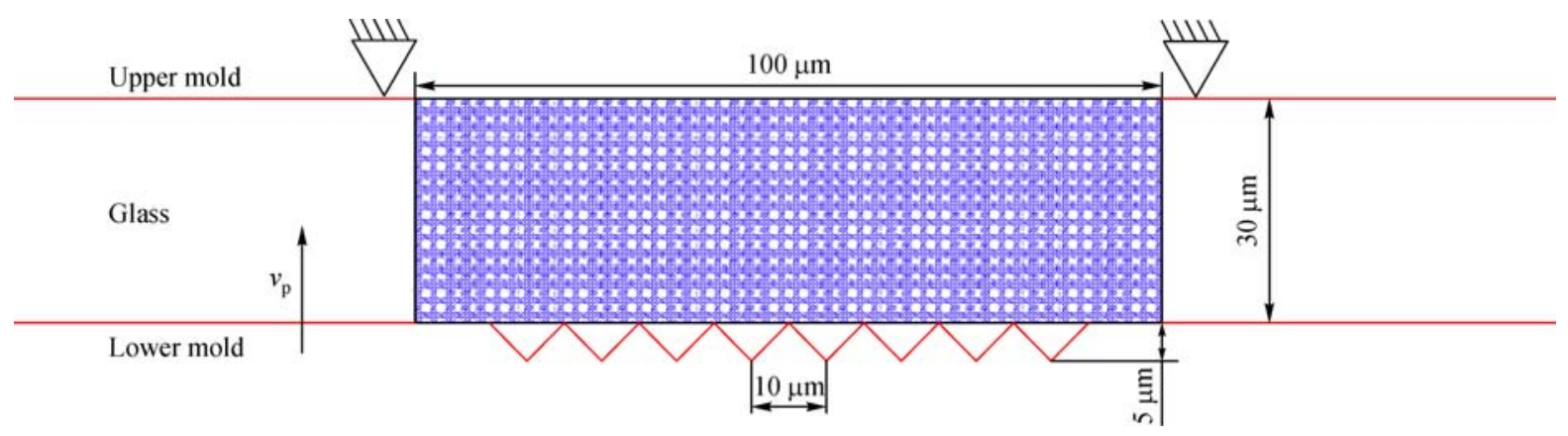

Fig. 15 2D simulation model of the GMP for microgrooves [35]

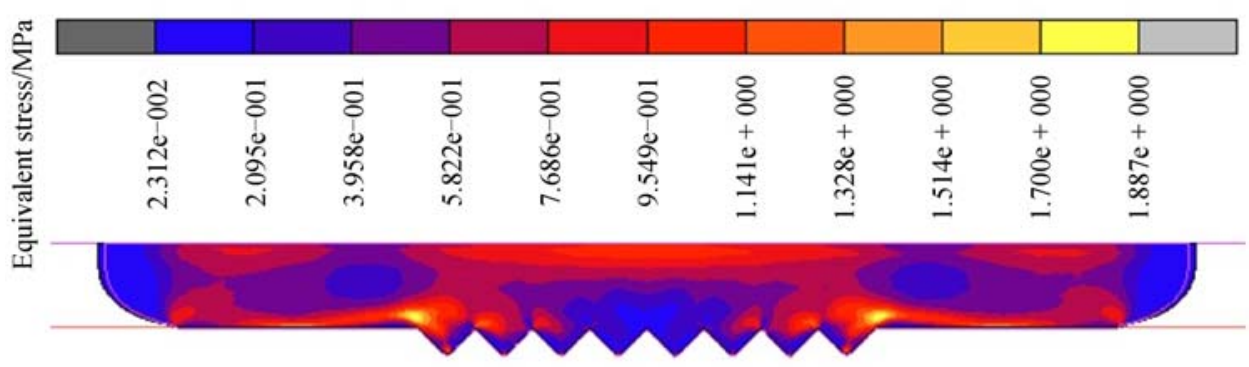

Fig. 16 Equivalent stress distribution at the molding temperature of $570{ }^{\circ} \mathrm{C}$ [35]

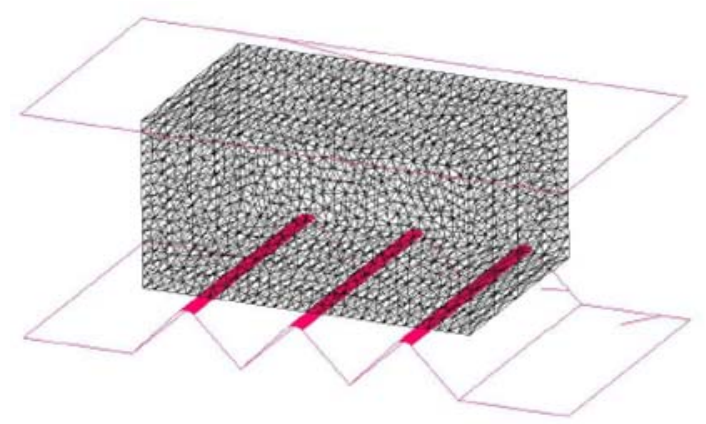

(a)

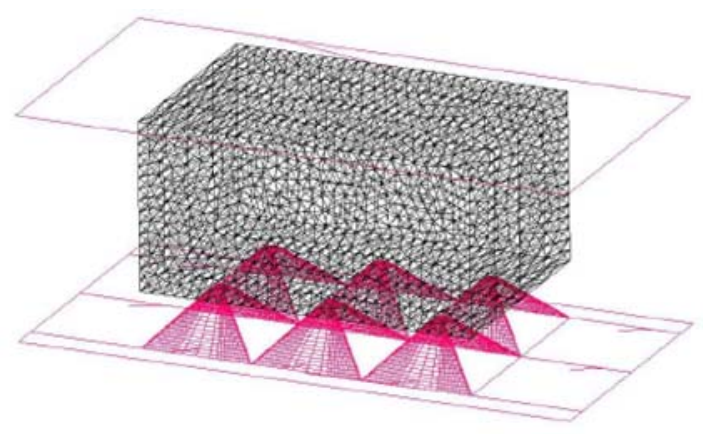

(b)

Fig. 17 GMP models for microstructures: (a) Microgrooves and (b) micropyramids [36]

A. Adjustment of the cylinder

(i) Cylinder 1 (heating 1)

Cylinder 1 increases the mold temperature with slight or without any pressure, and it adjusts the upward and downward positions depending on the weight of the cylinder. Cylinder 1 is also equipped with two regulators, a pressure adjuster, and an adjuster for mold contact. In this working position, the lens should be preliminarily heated to a high temperature in preparation for the next position.

(ii) Cylinders 2 and 3 (heating 2 and 3)

Cylinders 2 and 3 are primarily intended to apply slight pressure while raising the mold temperature. Thus, a proper pressure control must be implemented. In these two working positions, the lens should be heated to the molding temperature.

(iii) Cylinder 4 (pressing)

Cylinder 4 is primarily intended to facilitate actual molding. Optimum pressure control must be performed on the molds with the lens inside. Cylinder 4 is also equipped with a two-control system consisting of an electropneumatic regulator and a manual regulator.

(iv) Cylinders 5 and 6 (cooling 1 and 2)

Cylinders 5 and 6 are primarily intended to apply slight pressure and decrease the mold temperature. In these two working positions, the temperature of the lens should be reduced at a low speed to complete the annealing process. 


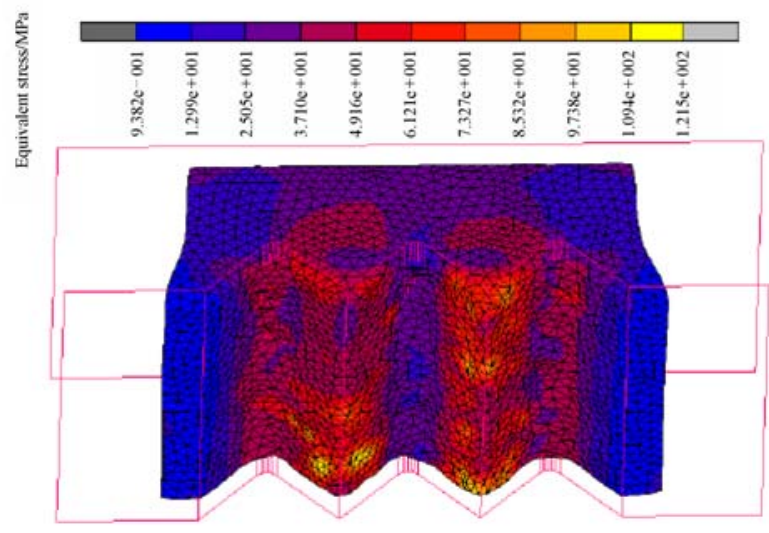

(a)

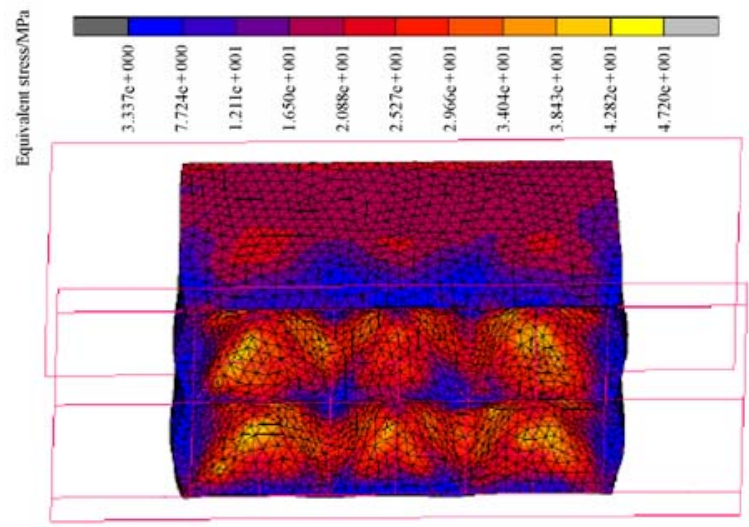

(b)

Fig. 18 Stress distribution in the glass during pressing: (a) Microgrooves and (b) micropyramids [36]

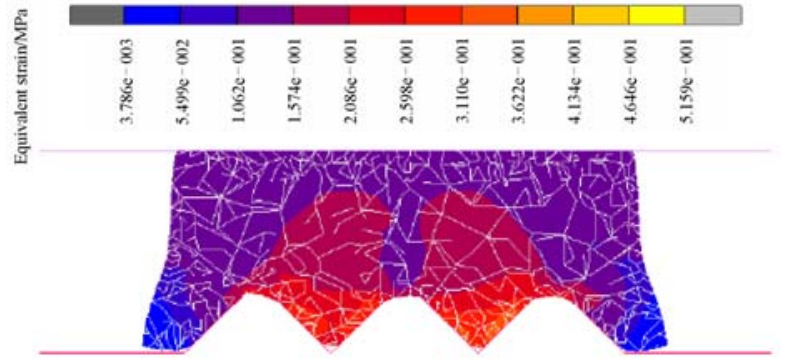

(a)

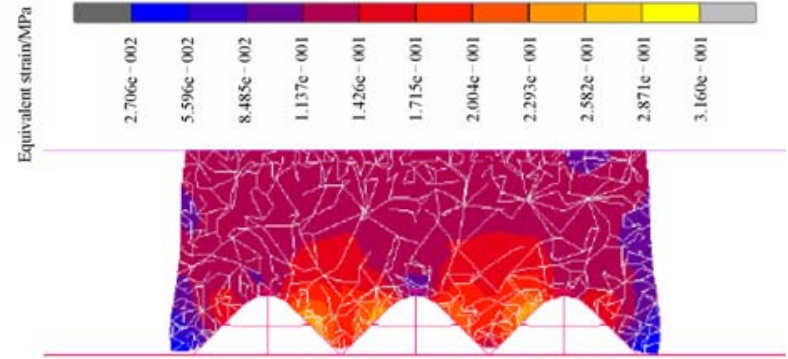

(b)

Fig. 19 Strain distribution in the glass during pressing: (a) Microgrooves and (b) micropyramids [36]
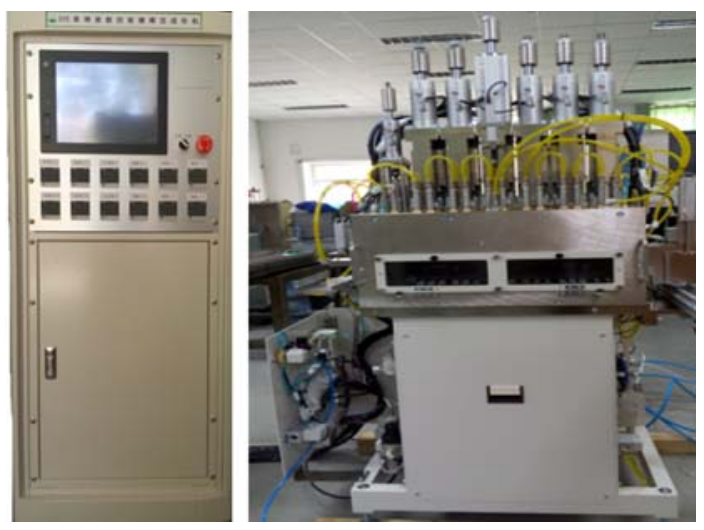

Fig. 20 Photograph of glass molding machine PFLF7-60A (SYS Co., Ltd., Japan)

(v) Cylinder 7 (cooling 3)

Cylinder 7 is mainly intended to decrease the mold temperature with slight or without any pressure. In this working position, the lens should be cooled to approximately $200{ }^{\circ} \mathrm{C}$.

B. Other adjustments

(i) Cooling water flow adjustment

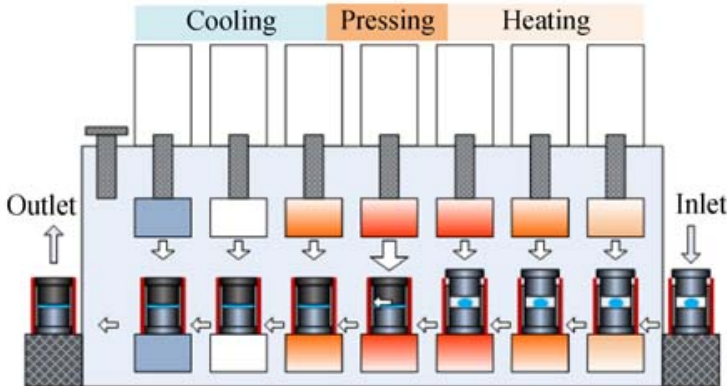

Fig. 21 Basic structure and functional features of glass molding machine PFLF7-60A

The flow rate can be confirmed at a flow rate meter of cooling water. In addition, the cooling water should flow and maintain a temperature of $20^{\circ} \mathrm{C}$ during the heating operation.

(ii) Nitrogen flow adjustment

A flowmeter can check the nitrogen pressure and adjust the nitrogen flow rate to the appropriate value through specific methods. Moreover, nitrogen flows through the driving time of the heating should never be interrupted. 


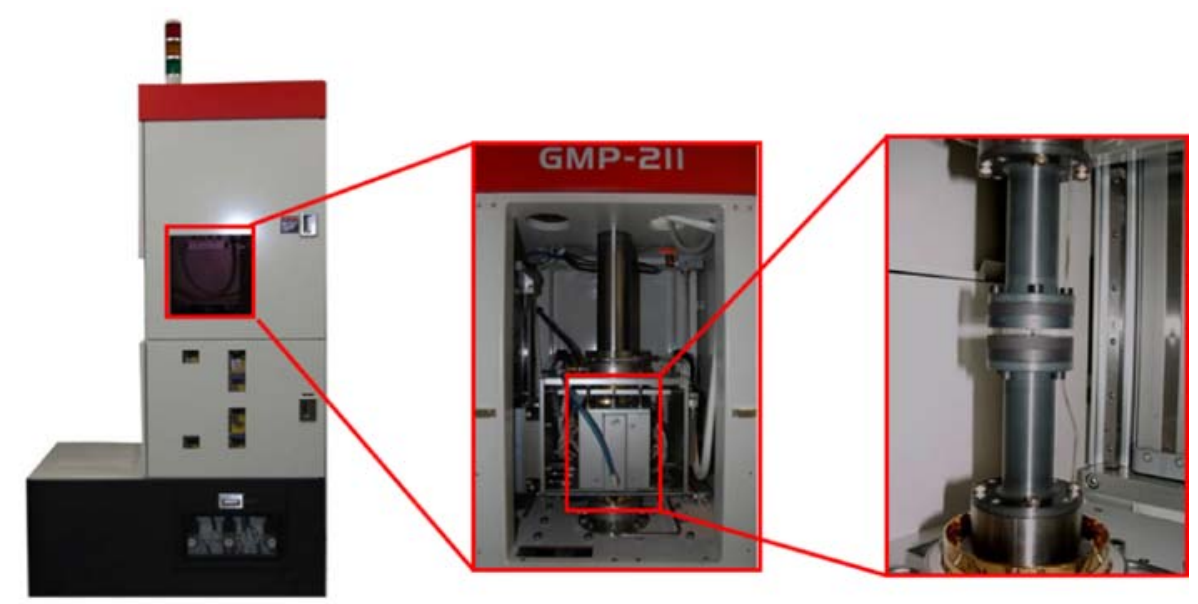

Fig. 22 Photograph of glass molding machine GMP211 (Toshiba Machine Co., Ltd., Japan) [38]

(iii) Air adjustment

The operating air of each cylinder is managed through one of the original regulators. During normal operation, the operating air should be adjusted to $0.5 \mathrm{MPa}$.

2) Glass molding machine GMP211

Figures 22 and 23 show the photograph and schematic of the ultra-precision glass molding machine GMP211 (Toshiba Corp., Shizuoka, Japan).

Having transfer performance at the nanometer level, the machine enables thermal transfer on glass, quartz, and plastic materials to produce various nanoimprinted products. In addition, this machine excels at reproducing molding conditions, and it provides stable quality among molded parts. Uniform and high-speed heating is realized via the infrared lamp. Meanwhile, nitrogen gas is used to purge the air to protect the molds from oxidation at high temperatures. The molding chamber is covered with a transparent silica glass tube, which allows infrared rays through but separates the nitrogen gas from the air outside. Once the glass preform reaches the molding temperature, the lower mold is driven upward to close the molds, whereas the upper mold is held stationary. Thus, microgrooves are formed. Annealing is then conducted to release the internal stress. Finally, the molded glass plate is cooled to room temperature naturally. Consequently, high-precision and high-quality optical elements can be produced with high productivity through heating, pressing, annealing, and cooling.

Table 1 presents typical molded products created through the glass molding machine; the products are obtained from the Toshiba Machine Co., Ltd. website.

3) Comparison between machine PFLF7-60A and GMP211

During the entire molding process, particularly the heating and pressing processes, the glass and the mold must cut off oxygen to prevent oxidation, which may damage the surface quality of the glass and reduce the service life of the mold. Current glass molding machines

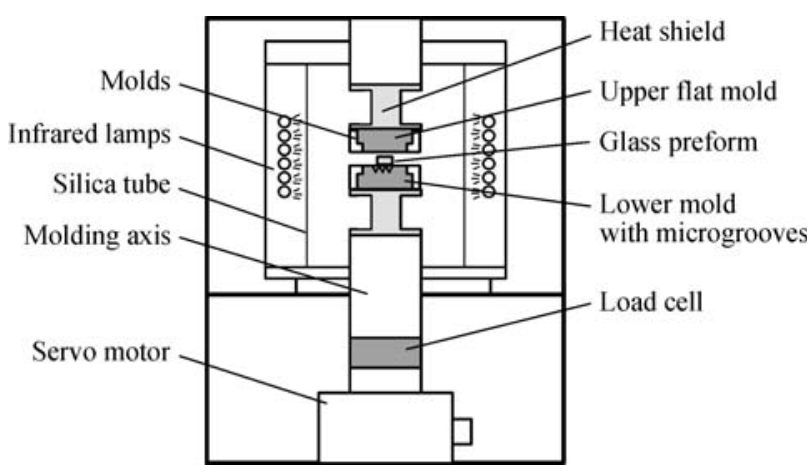

Fig. 23 Schematic diagram of the structure of the ultra-precision glass molding press machine GMP211 [35]

generally offer two ways to isolate oxygen. The GMP211 by Toshiba Machine Co., Ltd. provides a vacuum environment for lens fabrication, whereas the PFLF7$60 \mathrm{~A}$ by SYS Co., Ltd. offers a nitrogen environment. Both approaches of avoiding oxidation have advantages and disadvantages, as shown in Table 2. In addition, seven stations, namely, three heating stations, one pressing station, and three cooling stations, are placed in the PFLF7-60A machine to realize automatic production in the chamber simultaneously. By contrast, the GMP211 machine tends to be a more suitable for academic research, as it is more economic because the process occurs at one position.

4) Molding condition control

The thermal expansion of glass is also noteworthy. The volume-temperature relationship of a commonly used glass L-BAL42 (Ohara Corp., Kanagawa, Japan) is plotted in Fig. 24. The softening point $\left(P_{\mathrm{s}}\right)$ is defined as the temperature at which the glass deforms under its own weight and behaves as liquid. The yielding point $\left(A_{\mathrm{t}}\right)$, which is also called the "deformation point," is the temperature at which glass reaches its maximum expansion 
Table 1 Typical molded products from the website of Toshiba Machine Co., Ltd.

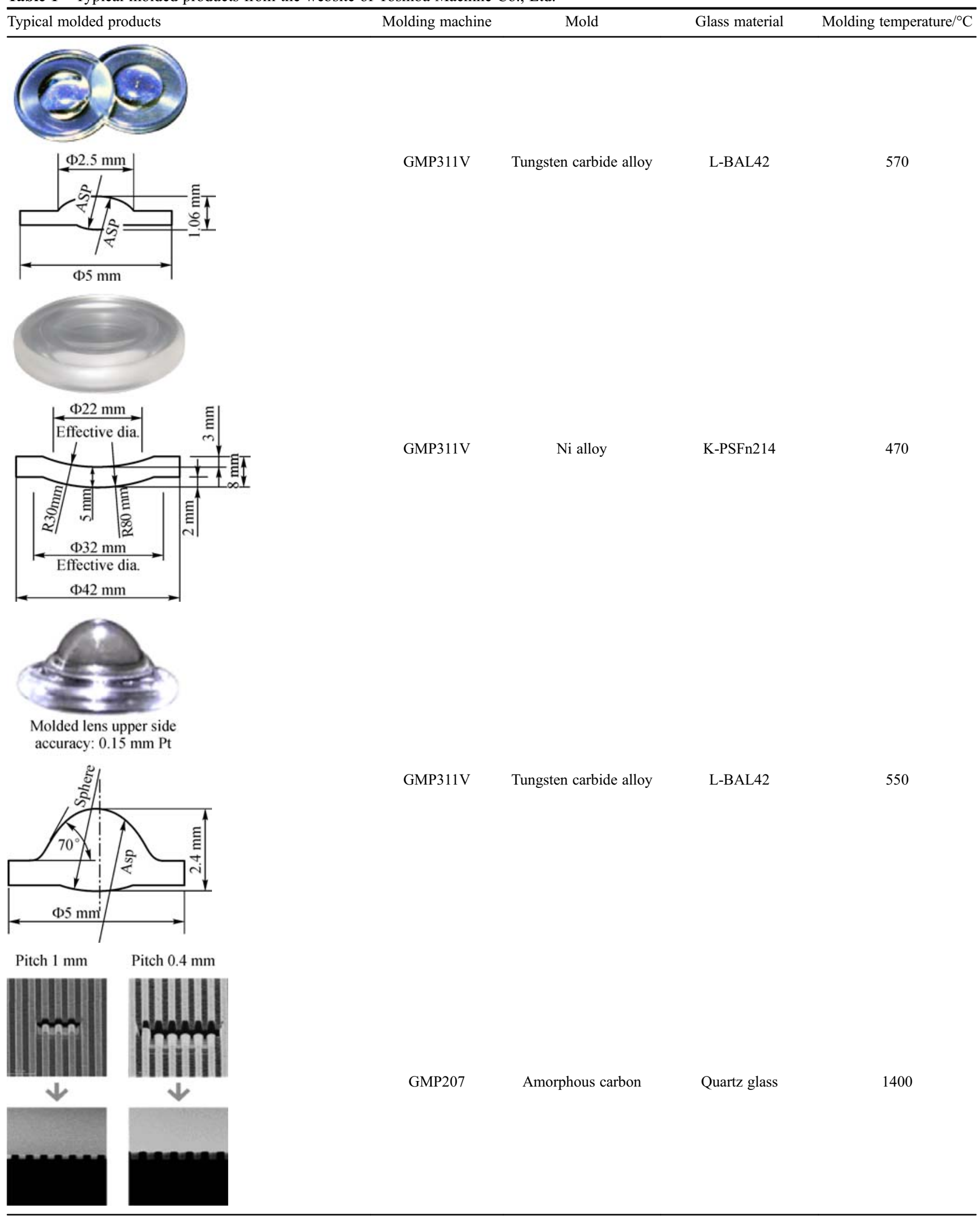




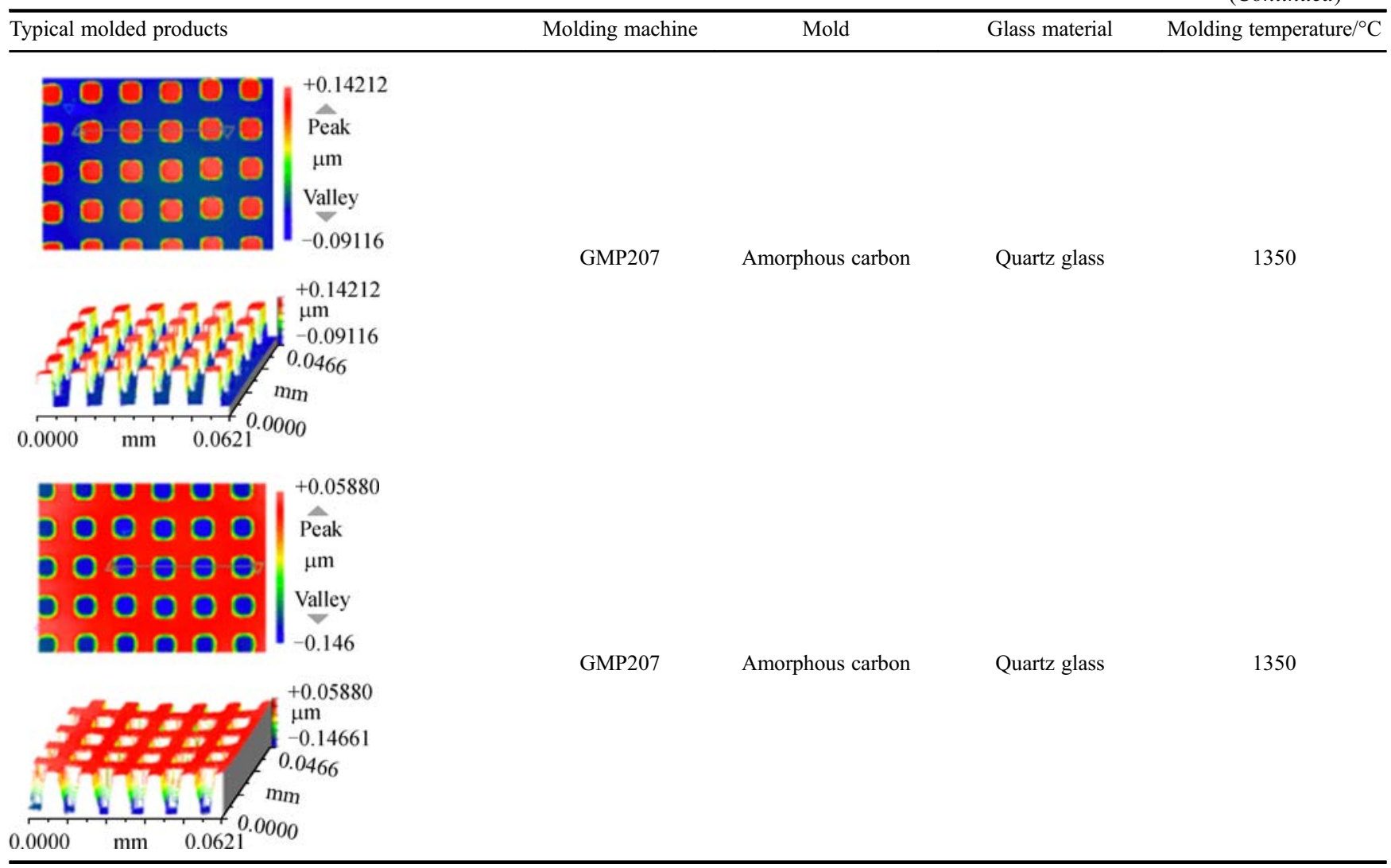

dia.: Diameter

Table 2 Advantages and disadvantages of vacuum and nitrogen environments

\begin{tabular}{lcc}
\hline Molding environment & Advantages & Disadvantages \\
\hline Vacuum environment & $\begin{array}{c}\text { Better effect on preventing } \\
\text { oxidation }\end{array}$ & High cost \\
Nitrogen environment & Easy operation & Air exhaust system \\
\hline
\end{tabular}

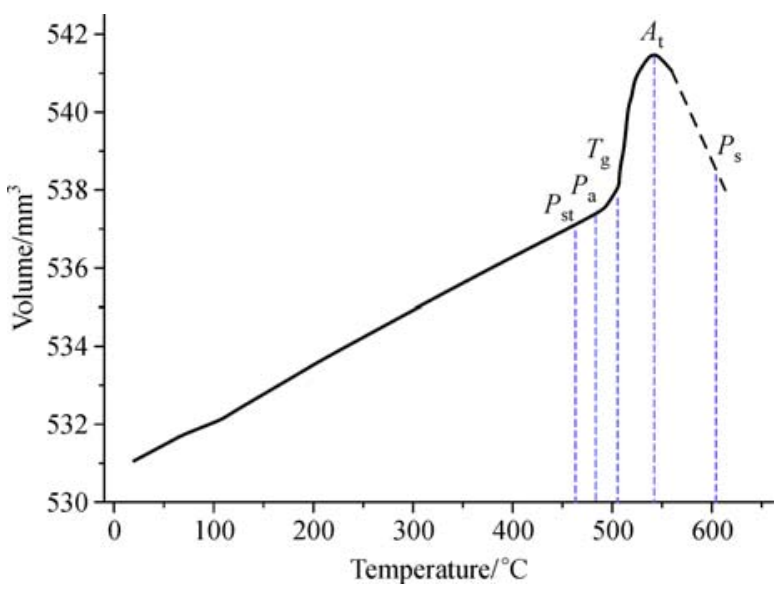

Fig. 24 Plot of volume change against temperature for a typical optical glass L-BAL42, showing strongly temperature-dependent thermal expansion characteristics [38] and low plasticity, and therefore starts to shrink. When such a melt is gradually cooled, the volume decreases abruptly to the transition temperature $\left(T_{\mathrm{g}}\right)$, below which volume shrinkage occurs at a slower rate. The pressing of a glass lens is always performed above $T_{\mathrm{g}}$. The annealing point $\left(P_{\mathrm{a}}\right)$ is the upper end of the annealing range for the pressed glass lens, at which the internal stress is reduced to a practically acceptable value over a short period. The strain point $\left(P_{\mathrm{st}}\right)$ represents the lower end of the annealing temperature range and the upper limit of the service temperature of a glass component. During annealing, glass is slowly cooled down from $P_{\mathrm{a}}$ to below $P_{\mathrm{st}}$.

Molding temperature should be carefully chosen for a good replication of optical microstructures. If pressing is performed above $A_{\mathrm{t}}$ and sustained to keep the shape of the lens during cooling, the volume expansion around $A_{\mathrm{t}}$ will lead to a sharp increase in the pressing load. In turn, the glass will adhere to the molds. By contrast, if pressing is conducted below $A_{\mathrm{t}}$, a high pressing load will be required because the glass is not sufficiently softened at this temperature range. In this case, significant residual stresses will occur in the glass lens, and the high pressing load may also shorten the service life of the molds. This problem is critical when molding micro Fresnel lenses and DOEs, in which the molds have extremely fine grooves on the surface. Therefore, a suitable temperature must be selected for the pressing in the GMP for microstructures. 
Another major issue in glass molding is the determination of the holding time and the holding pressure. Experiments have been conducted to explore the relationship between mold displacement and pressing load during creep and stress relaxation [1]. Figure 25 schematically shows the changes of the pressing load and the mold displacement in time sequence. Consequently, the holding time and the holding pressure for molding different types of glasses can be determined in the molding process depending on their time-pressing load value.

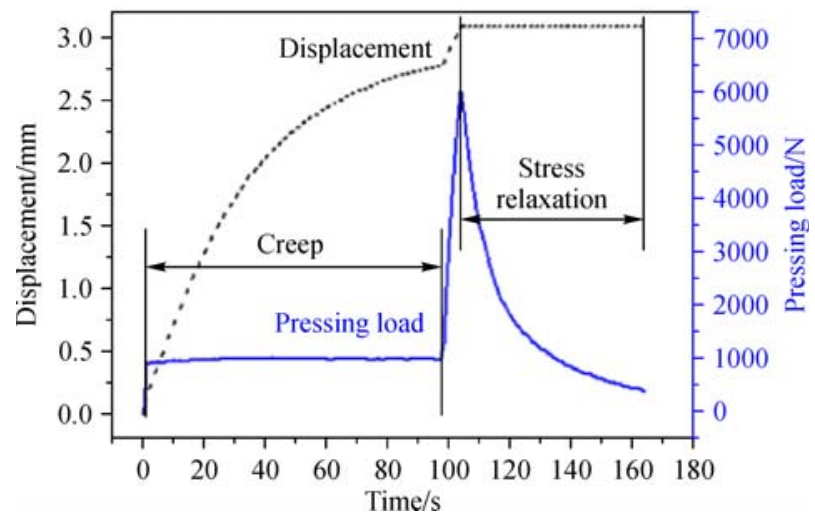

Fig. 25 Plots of mold displacement and pressing load in time sequence during creep and stress relaxation of glass [1]

\subsubsection{Test of molded microstructures}

Evaluating formed microstructures is important in the

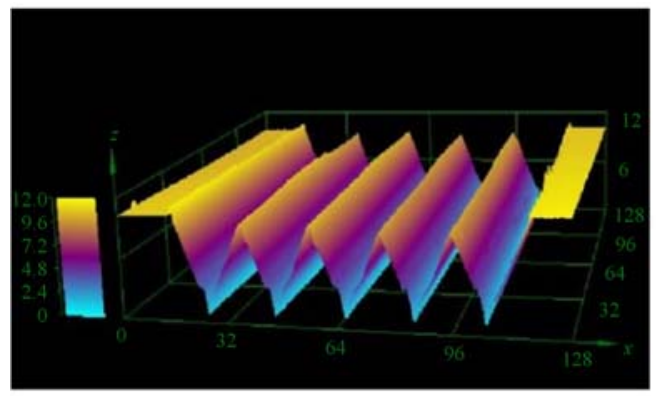

(a)

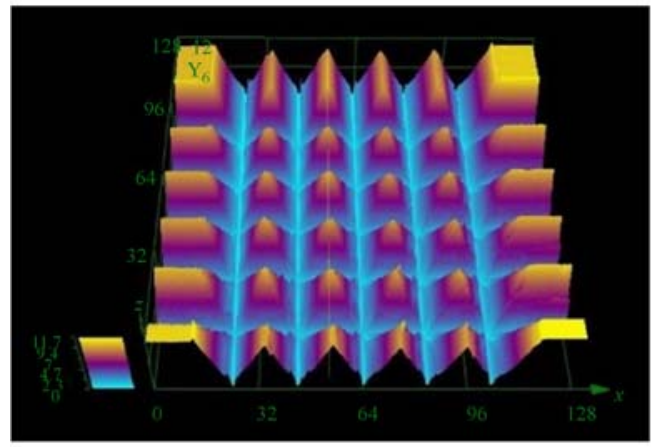

(c) study of optical microstructures along with the rapid development of measuring instruments. The microscope and the interferometer are the most extensively used measuring instruments because of their high accuracy, strong intuition, and user-friendly interface.

Microscopes have many types. The most widely used is the optical microscope, which uses light to image the sample. Other major types of microscopes are the electron microscope, including the transmission electron microscope and the scanning electron microscope, and the scanning probe microscope. The laser electron microscope LEXT OLS4100 is a new type of microscope that has gained popularity because of its quick imaging, aesthetics, and revolution of $0.12 \mu \mathrm{m}$. Figure 26 shows the laser scanning microscope photographs of the surface morphology of microgrooves and micropyramids molded through the PFLF7-60A. Figure 27 illustrates the microstructure profiles of the mold and the glass after the experiment.

\section{Glass-mold interface friction and adhesion}

\subsection{Incomplete filling in the glass molding process}

Microgroove forming generally suffers from low accuracy because of the incomplete filling of the material in the cavity of microgroove molds. Incomplete filling has become one of most notable molding defects in the GMP. As shown in Figs. 28 and 29, small portions of the

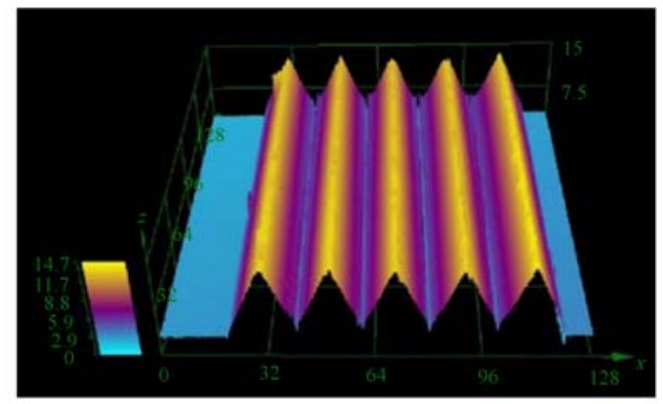

(b)

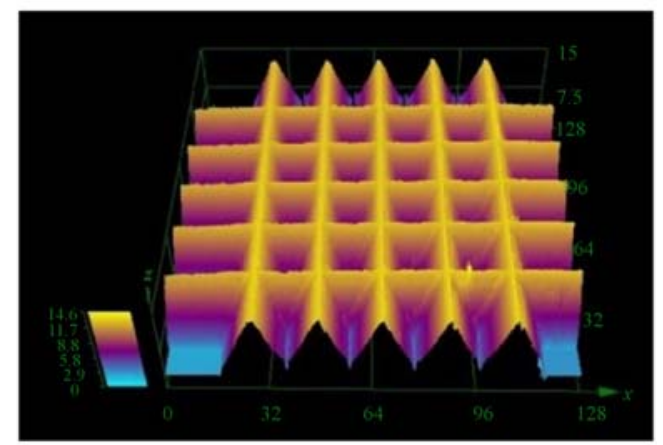

(d)

Fig. 26 Laser scanning microscope photographs of (a) microgroove mold, (b) molded microgroove glass, (c) micropyramid mold, and (d) molded micropyramid glass 


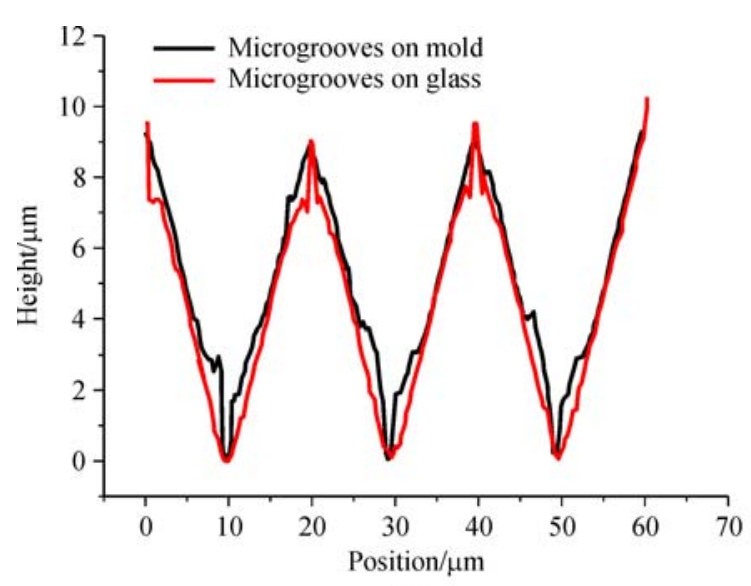

(a)

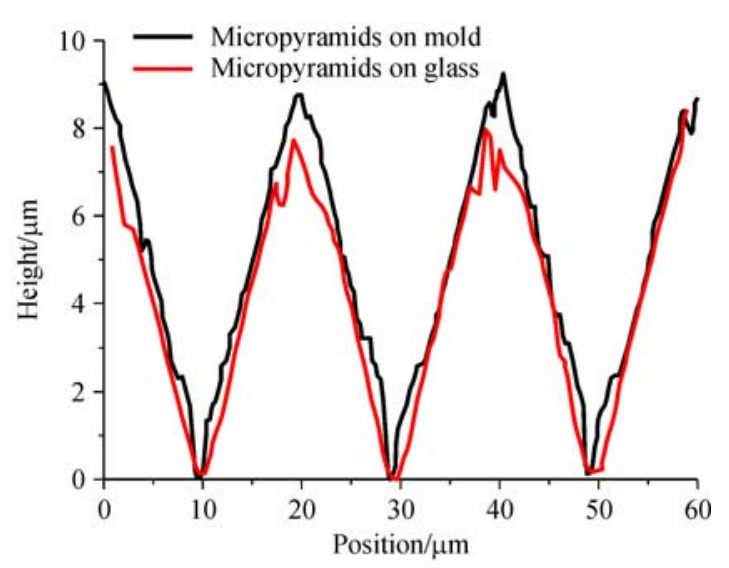

(b)

Fig. 27 Cross-sectional profiles of mold and glass after experiments. (a) Microgrooves; (b) micropyramids

glass stick to the mold, resulting in the high roughness on the mold surface and the incomplete filling of the molded glass. The interface friction between the glass and the mold are considered one of the reasons for the reduced incomplete filling in microstructures [67].

The filling behaviors of the glass at different friction coefficients are studied using ABAQUS. As shown in Fig. 30, the filling ratios of the glass tend to become larger as the friction coefficient decreases. Therefore, decreasing the friction coefficient between the glass and the mold is a feasible way to avoid the incomplete filling.

\subsection{Friction reduction through ultrasonic vibration}

Ultrasonic vibration has been recently proposed to improve the forming ability of the molding process [68-70]. To clarify the mechanism of ultrasonic vibration during the molding pressing, filling experiments are conducted on the PFLF7-60A (SYS Co., Ltd., Japan) (Fig. 20). Figure 31 shows a self-developed ultrasonic vibration-assisted molding machine, which is installed by the Advanced Machining Technology Laboratory in Beijing Institute of Technology. In addition, simulation using ABAQUS is

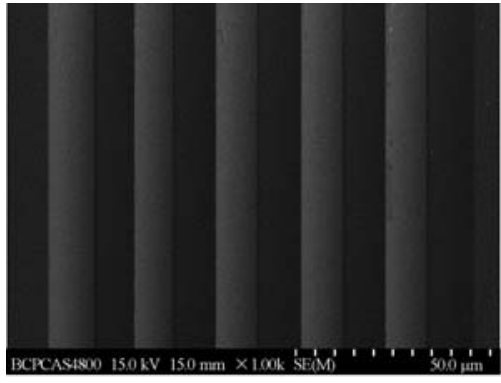

(a)

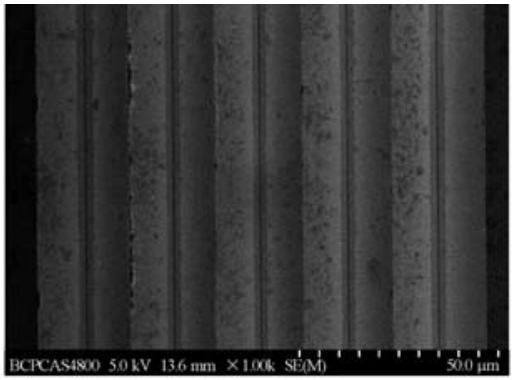

(b)

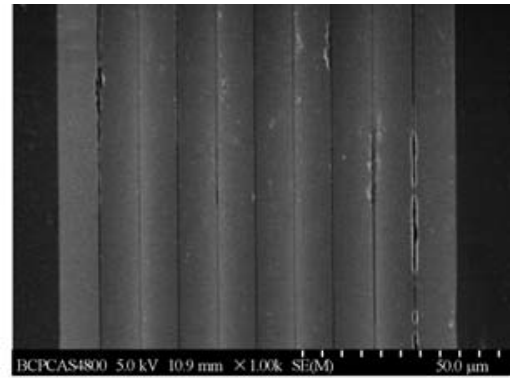

(c)

Fig. 28 SEM photographs of microgrooves. (a) Mold before molding process; (b) mold after molding process; (c) molded glass

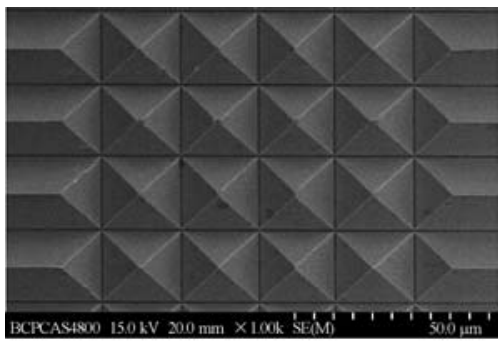

(a)

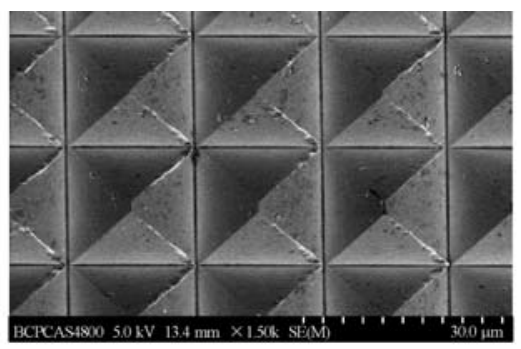

(b)

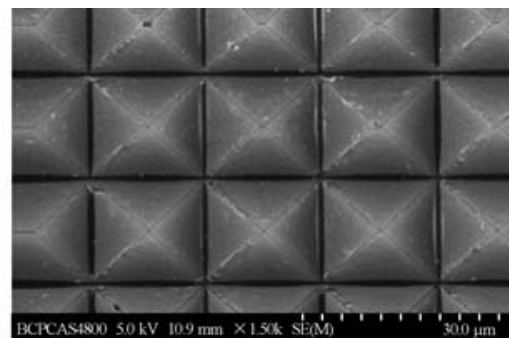

(c)

Fig. 29 SEM photographs of micropyramids. (a) Mold before molding process; (b) mold after molding process; (c) molded glass 


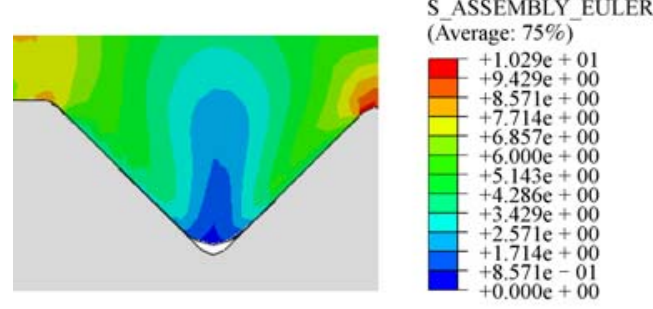

S ASSEMBLY EULER (Āverage: $75 \%$ )
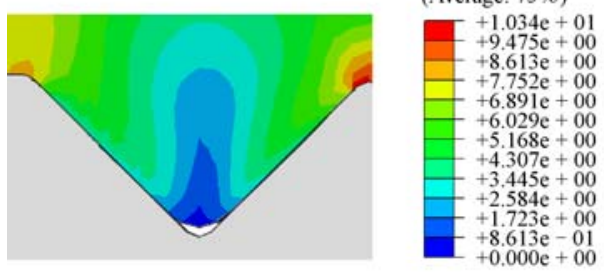

S ASSEMBLY EULER (Average: $75 \%$ )
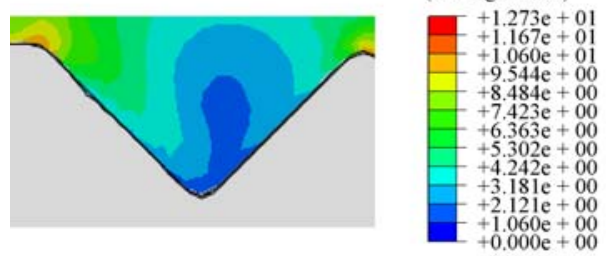

S ASSEMBLY EULER

(Average: $75 \%$ )

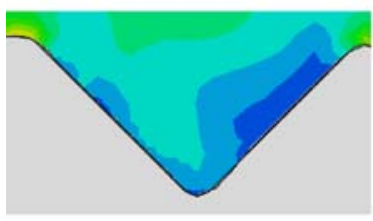

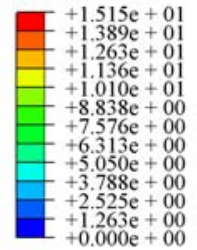

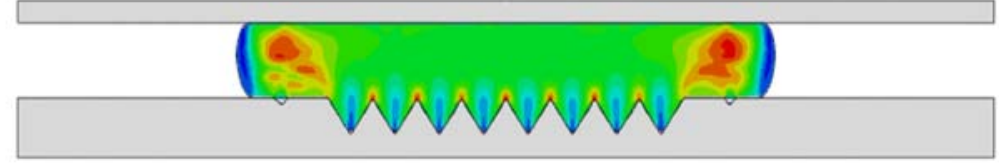

(a)

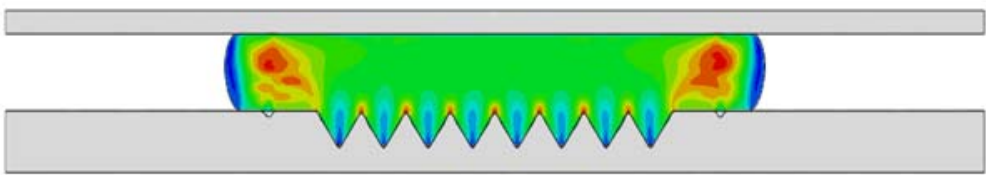

(b)

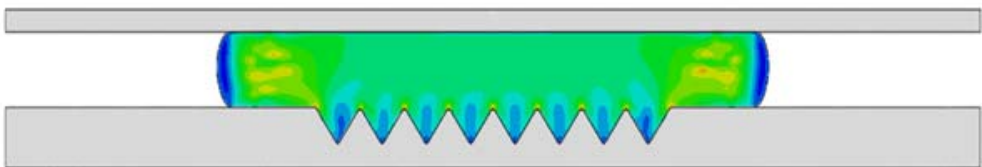

(c)

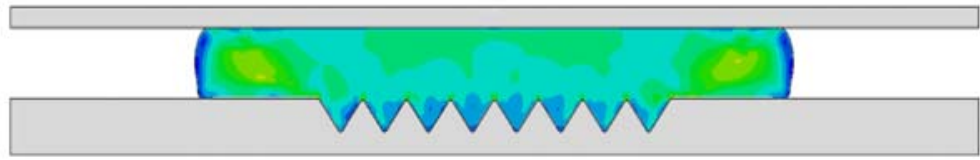

(d)

Fig. 30 Filling behaviors of the glass at different friction coefficients: (a) 0.5 , (b) 0.3 , (c) 0.1 , and (d) 0

also conducted to verify the filling ratio improvement caused by ultrasonic vibration.

As shown in Figs. 32 and 33, both the simulation and experiment results show that the glass-filled depth with ultrasonic vibration is significantly larger than the filling depth without ultrasonic vibration. Moreover, ultrasonic vibration can achieve a well-distributed internal stress and reduce the residual stress.

Interface friction between the mold and the glass can be resolved through the frictional contact model shown in Fig. 34. Given that both the Ni-P mold and the glass have a certain surface roughness, the compressive stress between the convex portion of the mold surface and the glass surface is much higher than that in other areas. Consequently, fracture has a higher probability of occurring in high-stress areas, indicating that the tangential motion at the glass-mold interface often causes portions of the glass material to separate from the glass surface and adhere to the mold surface. The ultrasonic vibration applied to the mold can significantly reduce the contact time between the mold and the glass, resulting in a decreased tangential motion and bonding probability. Thus, the stress concentration in the glass layer close to the mold is released presumably because of the reduced friction at high temperatures.

\subsection{Methods to increase mold life}

Additional steps can be added into the molding process to increase the mold life when no negative effects are introduced on form accuracy [71,72]. A two-step pressing method based on the conventional method is proposed. The first pressing step is performed at a high temperature near the softening point, such that the glass behaves as a viscous liquid, and most of the material deformation can be achieved at a low load. After the first step, the pressing load 


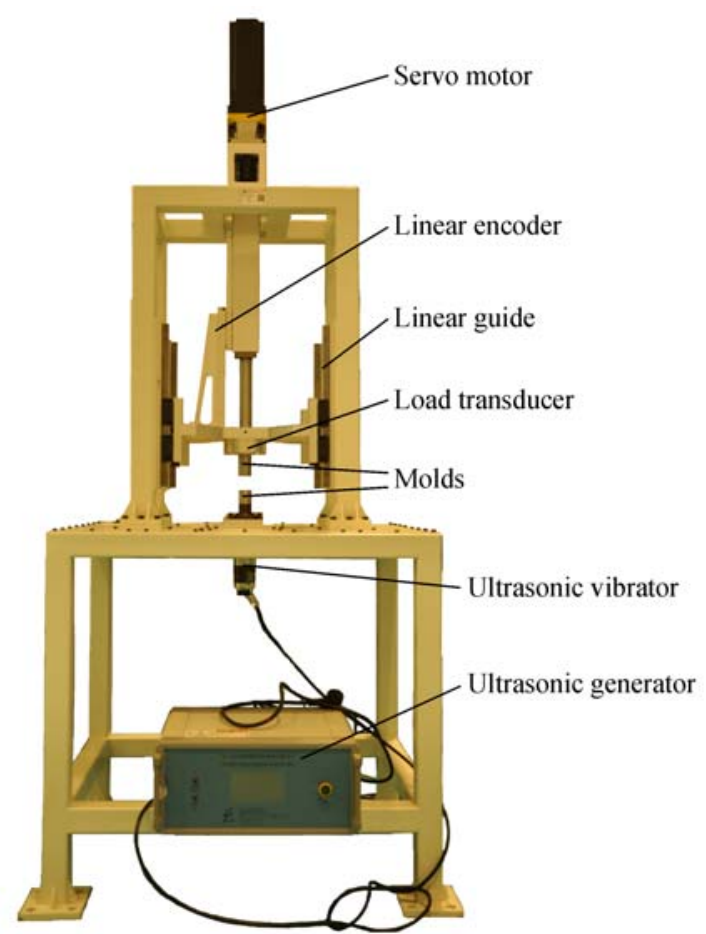

Fig. 31 Self-developed ultrasonic vibration-assisted molding machine

is reduced, and the temperature is lowered to a value between the transition point and the yielding point. Then, the second pressing is conducted at this temperature to close the molds and obtain the final shape of the lens. This two-step pressing method can achieve both high lens accuracy and long mold life.

Demolding ability is a crucial requirement of a mold for glass lenses. That is, the finished lens should be easily removable from the molds. In high-temperature glass molding, the surface of the mold tends to oxidize, and the oxidized material diffuses into the glass, causing adhesion of the glass lens to the mold. Therefore, a release agent is usually coated onto the surface of the mold to prevent oxidation. The lifetime of a mold is almost completely dependent to the release agent coating. The wearing and flaking of this coating reduces the lifetime of the mold. Moreover, the deterioration of the oxidation resistance of the release agent as a result of the in-diffusion of elements from the mold leads to an increased level of wettability by the glass, which further reduces the lifetime of the mold. Thus, the lifetime of the mold is influenced both by the interactions between the release agent and the mold and that between the release agent and the glass. Therefore, the selection of an appropriate release agent for the mold substrate is critical.

\section{Outlook}

In this paper, we presented an overview of the recent progress in optical microstructure fabrication through
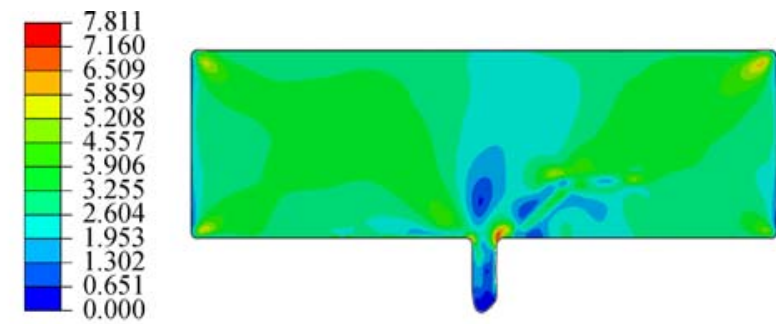

(b)

Fig. 32 Deformed glass shapes and equivalent stress distribution (a) without and (b) with ultrasonic vibration

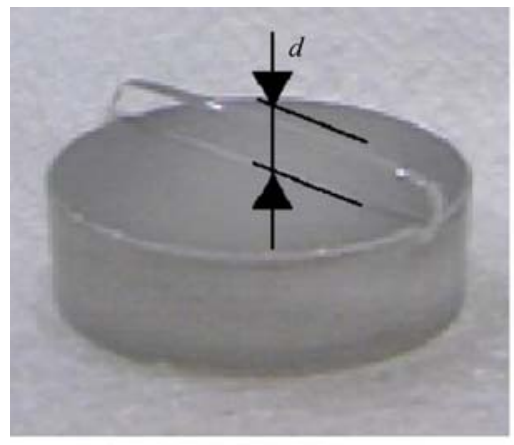

(a)

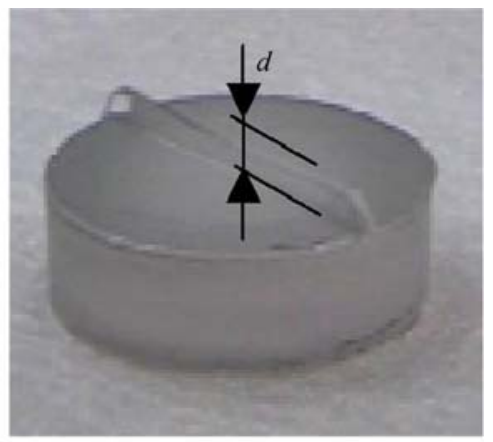

(b)

Fig. 33 Deformed glass shape after molding (a) without and (b) with ultrasonic vibration 


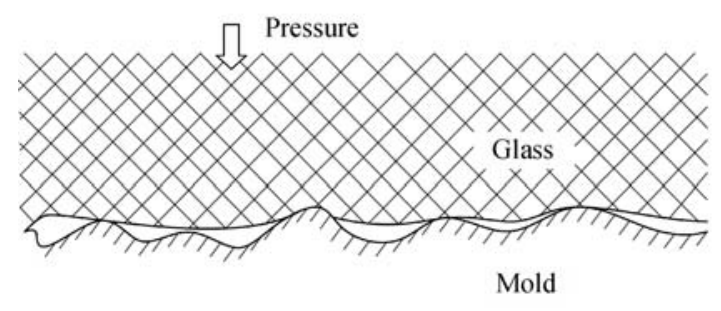

(a)

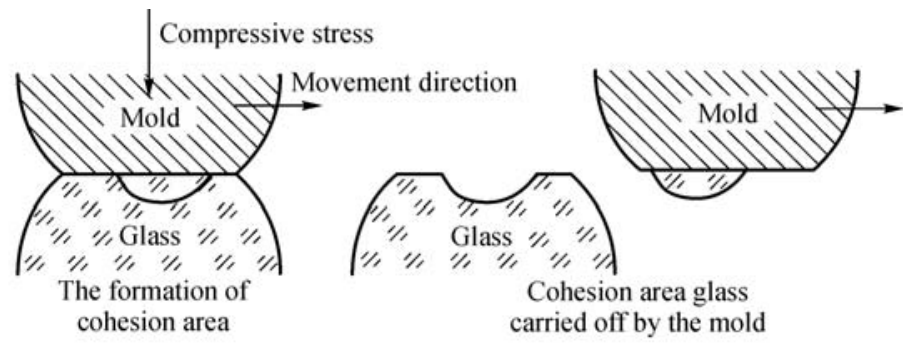

(b)

Fig. 34 Frictional contact model on the glass-mold interface. (a) Global view; (b) regional view

GMP. To date, several aspects in this area, such as glass molding technology, aspherical lens and microstructure Ni-P plating mold fabrication, and precise measuring instruments, are still at an immature phase. Other aspects, such as freeform microstructure mold design and fabrication, uniformity of the molded microstructures, conformity of microstructure shape in large-area fabrication [73-75], and new material preparation, exhibit great potential for next-generation molding processes despite being at their infancy.

1) Freeform microstructure fabrication

Optical systems using freeform lenses are becoming a viable solution to both imaging and nonimaging optics because of their capability to reduce the number of elements in an optical system and accurately control light irradiation. A freeform lens is loosely defined as an optical element that is not symmetric around its optical axis [7680].

Refractive freeform lens consists of two refractive freeform arrays containing $15 \times 9$ single freeform lenslets. Two glass wafers with lithographically structured apertures were bonded together to form a substrate containing three layers of apertures. Refractive freeform arrays are necessary in the constantly developing landscape for extending the image quality of artificial compound eye camera systems [81-85]. Given that freeform glass optics cannot be produced in a large volume through traditional processes, such as grinding, lapping, and polishing, the molding of glass microstructure optics has become a viable manufacturing process. However, replication requires a high-precision mold. Thus, the fabrication of freeform microstructures is expected to receive considerable research attention in the future.

2) Infrared material microstructures

"Infrared materials" is a general term for several kinds of materials. Among which, the most commonly used is the chalcogenide glass (in Fig. 35), which contains one or more chalcogenide elements (aside from oxygen) [86-88]. Glass-forming abilities decrease with increasing molar weight of constituent elements, i.e., $\mathrm{S}>\mathrm{Se}>\mathrm{Te}$. As an ordinary optical glass, chalcogenide glass is also moldable [89], which means complex shapes can be developed without using traditional expensive processes, such as single-point diamond turning or polishing. Infrared material microstructures will be widely used in various aspects of industrial and optical systems because of their semiconducting and physical properties, such as high refractive index, low phonon energy, and high nonlinearity $[90,91]$. A molding method significantly lowers the cost and improves the production. Thus, an increasing number of chalcogenide glass lenses will be made through the GMP in future.

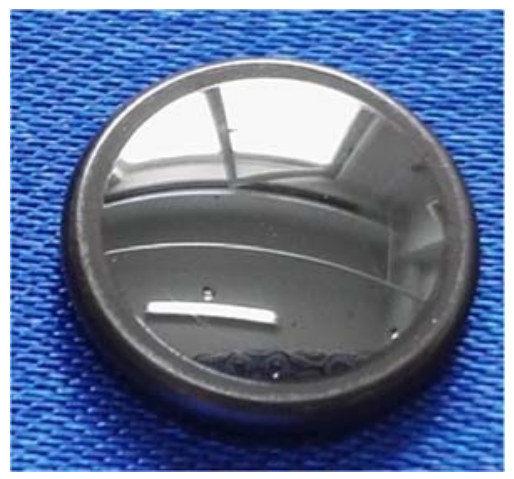

Fig. 35 Photograph of chalcogenide glass lens fabricated through GMP

Acknowledgements This work was supported by the National Basic Research Program of China (Grant No. 2015CB059900) and the National Natural Science Foundation of China (Grant No. 51375050).

Open Access This article is distributed under the terms of the Creative Commons Attribution 4.0 International License (http://creativecommons.org/ licenses/by/4.0/), which permits unrestricted use, distribution, and reproduction in any medium, provided you give appropriate credit to the original author(s) and the source, provide a link to the Creative Commons license, and indicate if changes were made.

\section{References}

1. Zhou T, Yan J, Masuda J, et al. Investigation on the viscoelasticity of optical glass in ultraprecision lens molding process. Journal of Materials Processing Technology, 2009, 209(9): 4484-4489

2. Madanipour K, Tavassoly M T. Moiré fringes as two-dimensional autocorrelation of transmission function of linear gratings and its 
application for modulation transfer function measurement. Optics and Lasers in Engineering, 2010, 48(1): 43-47

3. Morgan C J, Vallance R R, Marsh E R. Micro machining glass with polycrystalline diamond tools shaped by micro electro discharge machining. Journal of Micromechanics and Microengineering, 2004, 14(12): 1687-1692

4. Fang F, Chen L. Ultra-precision cutting for ZKN7 glass. CIRP Annals-Manufacturing Technology, 2000, 49(1): 17-20

5. Nicholas D J, Boon J E. The generation of high precision aspherical surfaces in glass by CNC machining. Journal of Physics D: Applied Physics, 1981, 14(4): 593-600

6. Ono T, Matsumura T. Influence of tool inclination on brittle fracture in glass cutting with ball end mills. Journal of Materials Processing Technology, 2008, 202(1-3): 61-69

7. Bouzid S, Bouaouadja N. Effect of impact angle on glass surfaces eroded by sand blasting. Journal of the European Ceramic Society, 2000, 20(4): 481-488

8. Chen S, Kwok H S. Light extraction from organic light-emitting diodes for lighting applications by sand-blasting substrates. Optics Express, 2010, 18(1): 37-42

9. Chen M, Shen M, Zhu S, et al. Effect of sand blasting and glass matrix composite coating on oxidation resistance of a nickel-based superalloy at $1000^{\circ} \mathrm{C}$. Corrosion Science, 2013, 73: 331-341

10. Revzin A, Russell R J, Yadavalli V K, et al. Fabrication of poly (ethylene glycol) hydrogel microstructures using photolithography. Langmuir, 2001, 17(18): 5440-5447

11. Ehrfeld W, Lehr H. Deep X-ray lithography for the production of three-dimensional microstructures from metals, polymers and ceramics. Radiation Physics and Chemistry, 1995, 45(3): 349-365

12. Totsu K, Fujishiro K, Tanaka S, et al. Fabrication of threedimensional microstructure using maskless gray-scale lithography. Sensors and Actuators A: Physical, 2006, 130-131: 387-392

13. Bassous E. Fabrication of novel three-dimensional microstructures by the anisotropic etching of (100) and (110) silicon. IEEE Transactions on Electron Devices, 1978, 25(10): 1178-1185

14. Jee S E, Lee P S, Yoon B J, et al. Fabrication of microstructures by wet etching of anodic aluminum oxide substrates. Chemistry of Materials, 2005, 17(16): 4049-4052

15. Murakami K, Wakabayashi Y, Minami K, et al. Cryogenic dry etching for high aspect ratio microstructures. In: Proceedings of An Investigation of Micro Structures, Sensors, Actuators, Machines and Systems, Micro Electro Mechanical Systems. IEEE, 1993

16. Sökmen Ü, Stranz A, Fündling S, et al. Capabilities of ICP-RIE cryogenic dry etching of silicon: Review of exemplary microstructures. Journal of Micromechanics and Microengineering, 2009, 19(10): 105005

17. Reyntjens S, Puers R. A review of focused ion beam applications in microsystem technology. Journal of Micromechanics and Microengineering, 2001, 11(4): 287-300

18. Wirth R. Focused ion beam (FIB) combined with SEM and TEM: Advanced analytical tools for studies of chemical composition, microstructure and crystal structure in geomaterials on a nanometre scale. Chemical Geology, 2009, 261(3-4): 217-229

19. Chao C, Shen S, Wu J. Fabrication of 3-D submicron glass structures by FIB. Journal of Materials Engineering and Performance, 2009, 18(7): 878-885
20. Mailis S, Zergioti I, Koundourakis G, et al. Etching and printing of diffractive optical microstructures by a femtosecond excimer laser. Applied Optics, 1999, 38(11): 2301-2308

21. Cao G, Konishi H, Li X. Mechanical properties and microstructure of SiC-reinforced $\mathrm{Mg}-(2,4) \mathrm{Al}-1 \mathrm{Si}$ nanocomposites fabricated by ultrasonic cavitation based solidification processing. Materials Science and Engineering: A, 2008, 486(1-2): 357-362

22. Däschner W, Long P, Stein R, et al. Cost-effective mass fabrication of multilevel diffractive optical elements by use of a single optical exposure with a gray-scale mask on high-energy beam-sensitive glass. Applied Optics, 1997, 36(20): 4675-4680

23. Pang Y K, Lee J C W, Lee H F, et al. Chiral microstructures (spirals) fabrication by holographic lithography. Optics Express, 2005, 13 (19): 7615-7620

24. LinC H, Lee G B, Chang B W, et al. A new fabrication process for ultra-thick microfluidic microstructures utilizing SU-8 photoresist. Journal of Micromechanics and Microengineering, 2002, 12(5): 590-597

25. Zhang C, Rentsch R, Brinksmeier E. Advances in micro ultrasonic assisted lapping of microstructures in hard-brittle materials: A brief review and outlook. International Journal of Machine Tools and Manufacture, 2005, 45(7-8): 881-890

26. Gottmann J, Hermans M, Ortmann J. Microcutting and hollow 3D microstructures in glasses by in-volume selective laser-induced etching (ISLE). Journal of Laser Micro/Nanoengineering, 2013, 8 (1): $15-18$

27. Piotter V, Bauer $\mathrm{W}$, Benzler $\mathrm{T}$, et al. Injection molding of components for microsystems. Microsystem Technologies, 2001, 7(3): 99-102

28. Liou A C, Chen R H. Injection molding of polymer micro-and submicron structures with high-aspect ratios. The International Journal of Advanced Manufacturing Technology, 2006, 28(11): 1097-1103

29. Lee H, Hong S, Yang K, et al. Fabrication of nano-sized resist patterns on flexible plastic film using thermal curing nano-imprint lithography. Microelectronic Engineering, 2006, 83(2): 323-327

30. Zhou T, Yan J, Yoshihara N, et al. Study on nonisothermal glass molding press for aspherical lens. Journal of Advanced Mechanical Design, Systems, and Manufacturing, 2010, 4(5): 806-815

31. Katsuki Masahide. Transferability of glass lens molding. Proceedings of SPIE, 2nd international Symposium on Advanced Optical Manufacturing and Testing Technologies: Advanced Optical Manufacturing Technologies, 2006, 61490M

32. Aono Y, Negishi M, Takano J. Development of large-aperture aspherical lens with glass molding. Proceedings of SPIE, Advanced Optical Manufacturing and Testing Technology, 2000, 4231: 16-23

33. Zhou T, Yan J, Yoshihara N, et al. Shape compensation of the molding dies in glass molding press for aspherical lens. In: Proceedings of the 9th international conference on frontiers of design and manufacturing. 2010

34. Zhou T, Yan J, Kuriyagawa T. High-efficiency and ultra-precision glass molding of aspherical lens and microstructures. In: Proceedings of International Symposium on Ultraprecision Engineering and Nanotechnology. 2011

35. Zhou T, Yan J, Masuda J, et al. Investigation on shape transferability in ultraprecision glass molding press for microgrooves. Precision Engineering, 2011, 35(2): 214-220 
36. Zhou T, Ji W, Kuriyagawa T. Comparing microgroove array forming with micropyramid array forming in the glass molding press. Key Engineering Materials, 2010, 447-448: 361-365

37. Pan $\mathrm{C}, \mathrm{Wu} \mathrm{T}$, Chen $\mathrm{M}$, et al. Hot embossing of micro-lens array on bulk metallic glass. Sensors and Actuators A: Physical, 2008, 141 (2): 422-431

38. Yan J, Zhou T, Masuda J, et al. Modeling high-temperature glass molding process by coupling heat transfer and viscous deformation analysis. Precision Engineering, 2009, 33(2): 150-159

39. Yan J, Oowada T, Zhou T, et al. Precision machining of microstructures on electroless-plated NiP surface for molding glass components. Journal of Materials Processing Technology, 2009, 209(10): 4802-4808

40. Barbacki A, Kawalec M, Hamrol A. Turning and grinding as a source of microstructural changes in the surface layer of hardened steel. Journal of Materials Processing Technology, 2003, 133(1-2): $21-25$

41. Cao D M, Jiang J, Meng W, et al. Fabrication of high-aspect-ratio microscale Ta mold inserts with micro electrical discharge machining. Microsystem technologies, 2007, 13(5): 503-510

42. Bojorquez B, Marloth R T, Es-Said O S. Formation of a crater in the workpiece on an electrical discharge machine. Engineering Failure Analysis, 2002, 9(1): 93-97

43. Guu Y H, Hocheng H, Tai N H, et al. Effect of electrical discharge machining on the characteristics of carbon fiber reinforced carbon composites. Journal of Materials Science, 2001, 36(8): 2037-2043

44. Huang M, Chiang Y, Lin S, et al. Fabrication of microfluidic chip using micro-hot embossing with micro electrical discharge machining mold. Polymers for Advanced Technologies, 2012, 23(1): $57-64$

45. Reynaerts D, Meeusen W, Van Brussel H. Machining of threedimensional microstructures in silicon by electro-discharge machining. Sensors and Actuators A: Physical, 1998, 67(1-3): 159-165

46. Yan J, Horikoshi A, Kuriyagawa T, et al. Manufacturing structured surface by combining microindentation and ultraprecision cutting. CIRP Journal of Manufacturing Science and Technology, 2012, 5 (1): 41-47

47. Takahashi M, Sugimoto K, Maeda R. Nanoimprint of glass materials with glassy carbon molds fabricated by focused-ion-beam etching. Japanese Journal of Applied Physics, 2005, 44(7B): 5600

48. Marty F, Rousseau L, Saadany B, et al. Advanced etching of silicon based on deep reactive ion etching for silicon high aspect ratio microstructures and three-dimensional micro-and nanostructures. Microelectronics Journal, 2005, 36(7): 673-677

49. Tanaka S, Rajanna K, Abe T, et al. Deep reactive ion etching of silicon carbide. Journal of Vacuum Science \& Technology B, 2001, 19(6): 2173-2176

50. Youn S W, Takahashi M, Goto H, et al. Microstructuring of glassy carbon mold for glass embossing-Comparison of focused ion beam, nano/femtosecond-pulsed laser and mechanical machining. Microelectronic Engineering, 2006, 83(11-12): 2482-2492

51. Wurtz M Ad. On the hydruret of copper. Philosophical Magazine Series 3, 1844, 25(164): 154-156

52. Brenner A, Riddell G E. Nickel plating on steel by chemical reduction. Journal of Research of the National Bureau of Standards, 1946, 37(1): 31-34
53. Brenner A, Riddell G E. Deposition of nickel and cobalt by chemical reduction. Journal of Research of the National Bureau of Standards, 1947, 39(5): 385-395

54. Krishnan K H, John S, Srinivasan K N, et al. An overall aspect of electroless Ni-P depositions-A review article. Metallurgical and Materials Transactions A, 2006, 37(6): 1917-1926

55. Strafford K N, Datta P K, O'donnell A K. Electroless nickel coatings: Their application, evaluation \& production techniques. Materials \& Design, 1982, 3(6): 608-614

56. Nakasuji T, Kodera S, Hara S, et al. Diamond turning of brittle materials for optical components. CIRP Annals-Manufacturing Technology, 1990, 39(1): 89-92

57. Casstevens J M, Daugherty C E. Diamond turning optical surfaces on electroless nickel. Proceedings of SPIE, Precision Machining of Optics, 1978, 159: 109

58. Zhou T, Yan J, Liang Z, et al. Development of polycrystalline Ni-P mold by heat treatment for glass microgroove forming. Precision Engineering, 2015, 39: 25-30

59. Liu Y, Zhao W, Zhou $\mathrm{T}$, et al. Microgroove machining on crystalline nickel phosphide plating by single-point diamond cutting. International Journal of Advanced Manufacturing Technology (in press)

60. Guo Z, Keong K G, Sha W. Crystallisation and phase transformation behaviour of electroless nickel phosphorus platings during continuous heating. Journal of Alloys and Compounds, 2003, 358(1-2): $112-119$

61. Chern G L. Experimental observation and analysis of burr formation mechanisms in face milling of aluminum alloys. International Journal of Machine Tools and Manufacture, 2006, 46(12-13): $1517-1525$

62. Dornfeld D A, Kim J S, Dechow H, et al. Drilling burr formation in titanium alloy, Ti-6AI-4V. CIRP Annals-Manufacturing Technology, 1999, 48(1): 73-76

63. Guo Y B, Dornfeld D A. Finite element modeling of burr formation process in drilling 304 stainless steel. Journal of Manufacturing Science and Engineering, 2000, 122(4): 612-619

64. Jain A, Yi A Y. Numerical modeling of viscoelastic stress relaxation during glass lens forming process. Journal of the American Ceramic Society, 2005, 88(3): 530-535

65. Yi A Y, Jain A. Compression molding of aspherical glass lenses-A combined experimental and numerical analysis. Journal of the American Ceramic Society, 2005, 88(3): 579-586

66. Jain A, Firestone G C, Yi A Y. Viscosity measurement by cylindrical compression for numerical modeling of precision lens molding process. Journal of the American Ceramic Society, 2005, 88(9): 2409-2414

67. Jung W, Lee H J, Park K. Investigation of localized heating characteristics in selective ultrasonic imprinting. International Journal of Precision Engineering and Manufacturing, 2015, 16(9): 1999-2004

68. Xie J, Zhou T, Liu Y, et al. The effects of ultrasonic vibration in hot pressing for microgrooves. Materials Science Forum, 2016, 861: $121-126$

69. Xie J, Zhou T, Liu Y, et al. Mechanism study on microgroove forming by ultrasonic vibration assisted hot pressing. Precision Engineering, 2016, 46: 270-277 
70. Chen J, Chen Y, Li H, et al. Physical and chemical effects of ultrasound vibration on polymer melt in extrusion. Ultrasonics Sonochemistry, 2010, 17(1): 66-71

71. Masuda J, Yan J, Tashiro T, et al. Microstructural and topographical changes of Ni-P plated moulds in glass lens pressing. International Journal of Surface Science and Engineering, 2009, 3(1-2): 86102

72. Masuda J, Yan J, Zhou T, et al. Thermally induced atomic diffusion at the interface between release agent coating and mould substrate in a glass moulding press. Journal of Physics D: Applied Physics, 2011, 44(21): 215302

73. Schmidt M S, Hübner J, Boisen A. Large area fabrication of leaning silicon nanopillars for surface enhanced Raman spectroscopy. Advanced Materials, 2012, 24(10): OP11-OP18

74. Guo C, Feng L, Zhai J, et al. Large-area fabrication of a nanostructure-induced hydrophobic surface from a hydrophilic polymer. ChemPhysChem, 2004, 5(5): 750-753

75. Gao W, Araki T, Kiyono S, et al. Precision nano-fabrication and evaluation of a large area sinusoidal grid surface for a surface encoder. Precision Engineering, 2003, 27(3): 289-298

76. Khorasaninejad M, Chen W T, Devlin R C, et al. Metalenses at visible wavelengths: Diffraction-limited focusing and subwavelength resolution imaging. Science, 2016, 352(6290): 1190-1194

77. Dunkel J, Wippermann F, Reimann A, et al. Fabrication of microoptical freeform arrays on wafer level for imaging applications. Optics Express, 2015, 23(25): 31915-31925

78. Brückner A, Leitel R, Oberdörster A, et al. Multi-aperture optics for wafer-level cameras. Journal of Micro/Nanolithography, MEMS, and MOEMS, 2011, 10(4): 043010

79. Li L, Yi A Y. Design and fabrication of a freeform prism array for 3D microscopy. Journal of the Optical Society of America A, 2010, 27(12): 2613-2620

80. Wippermann F C, Radtke D, Zeitner U, et al. Fabrication technologies for chirped refractive microlens arrays. Proceedings of SPIE, Current Developments in Lens Design and Optical Engineering VII, 2006, 6288: 628800

81. Li L, Yi A Y. Design and fabrication of a freeform microlens array for a compact large-field-of-view compound-eye camera. Applied Optics, 2012, 51(12): 1843-1852

82. Li L, Yi A Y. Design and fabrication of a freeform microlens array for uniform beam shaping. Microsystem Technologies, 2011, 17 (12): 1713-1720

83. Duparré J, Wippermann F, Dannberg P, et al. Chirped arrays of refractive ellipsoidal microlenses for aberration correction under oblique incidence. Optics Express, 2005, 13(26): 10539-10551

84. Scheiding S, Yi A Y, Gebhardt A, et al. Freeform manufacturing of a microoptical lens array on a steep curved substrate by use of a voice coil fast tool servo. Optics Express, 2011, 19(24): 23938-23951

85. Cheng D, Wang Y, Hua H, et al. Design of an optical see-through head-mounted display with a low f-number and large field of view using a freeform prism. Applied Optics, 2009, 48(14): 2655-2668

86. Asobe M. Nonlinear optical properties of chalcogenide glass fibers and their application to all-optical switching. Optical Fiber Technology, 1997, 3(2): 142-148

87. Sanghera J S, Aggarwal I D. Active and passive chalcogenide glass optical fibers for IR applications: A review. Journal of NonCrystalline Solids, 1999, 256-257: 6-16

88. Zhang X, Guimond Y, Bellec Y. Production of complex chalcogenide glass optics by molding for thermal imaging. Journal of Non-Crystalline Solids, 2003, 326-327: 519-523

89. Aitken B G, Currie S C, Monahan B C, et al. US Patent 7330634. 2008-02-12

90. Liao M, Chaudhari C, Qin G, et al. Fabrication and characterization of a chalcogenide-tellurite composite microstructure fiber with high nonlinearity. Optics Express, 2009, 17(24): 21608-21614

91. Brilland L, Smektala F, Renversez G, et al. Fabrication of complex structures of holey fibers in chalcogenide glass. Optics Express, 2006, 14(3): 1280-1285 